\title{
Reelin Prevents Apical Neurite Retraction during Terminal Translocation and Dendrite Initiation
}

\author{
Ryan S. O'Dell, ${ }^{1}$ David A. Cameron, ${ }^{1}$ Warren R. Zipfel, ${ }^{2}$ and Eric C. Olson ${ }^{1}$ \\ ${ }^{1}$ Department of Neuroscience and Physiology, SUNY Upstate Medical University, Syracuse, New York 13210, and ${ }^{2}$ Department of Biomedical \\ Engineering, Cornell University, Ithaca, New York 14853
}

The mechanisms controlling cortical dendrite initiation and targeting are poorly understood. Multiphoton imaging of developing mouse cortex reveals that apical dendrites emerge by direct transformation of the neuron's leading process during the terminal phase of neuronal migration. During this $\sim 110$ min period, the dendritic arbor increases $\sim 2.5$-fold in size and migration arrest occurs below the first stable branch point in the developing arbor. This dendritic outgrowth is triggered at the time of leading process contact with the marginal zone (MZ) and occurs primarily by neurite extension into the extracellular matrix of the MZ. In reeler cortices that lack the secreted glycoprotein Reelin, a subset of neurons completed migration but then retracted and reorganized their arbor in a tangential direction away from the MZ soon after migration arrest. For these reeler neurons, the tangential oriented primary neurites were longer lived than the radially oriented primary neurites, whereas the opposite was true of wild-type (WT) neurons. Application of Reelin protein to reeler cortices destabilized tangential neurites while stabilizing radial neurites and stimulating dendritic growth in the MZ. Therefore, Reelin functions as part of a polarity signaling system that links dendritogenesis in the MZ with cellular positioning and cortical lamination.

Key words: dendritogenesis; lissencephaly; mental retardation; polarity

\section{Significance Statement}

Whether the apical dendrite emerges by transformation of the leading process of the migrating neuron or emerges de novo after migration is completed is unclear. Similarly, it is not clear whether the secreted glycoprotein Reelin controls migration and dendritic growth as related or separate processes. Here, multiphoton microscopy reveals the direct transformation of the leading process into the apical dendrite. This transformation is coupled to the successful completion of migration and neuronal soma arrest occurs below the first stable branch point of the nascent dendrite. Deficiency in Reelin causes the forming dendrite to avoid its normal target area and branch aberrantly, leading to improper cellular positioning. Therefore, this study links Reelindependent dendritogenesis with migration arrest and cortical lamination.

\section{Introduction}

Excitatory projection neurons in the cortex are highly polarized, having an apical dendrite and descending axon (Ramon y Cajal,

Received April 27, 2015; revised June 2, 2015; accepted June 8, 2015.

Author contributions: R.S.O., D.A.C., W.R.Z., and E.C.0. designed research; R.S.0. performed research; R.S.0. and E.C.O. analyzed data; R.S.O., D.A.C., and E.C.O. wrote the paper.

The work was supported by grants from the National Institute of Neurological Disorders and Stroke-National Institutes of Health (Grant NS066071 to E.C.0.) and the National Institute of Biomedical Imaging and Bioengineering-National Institutes of Health (Grant P41-RR04224 to W.R.Z.). Student support was provided by the SUNY Upstate College of Graduate Studies, Department of Neuroscience and Physiology, Syracuse, New York. We thank Michael Frotscher (University of Freiburg) for the stable cell line expressing Reelin; Mary Beth Hatten (Rockefeller University) for providing the Gensat Pde1C:::GFP mice; Teiichi Furuichi (Tokyo University of Science) for the pCAGGSmRFP plasmid; Roger Tsien (University of California, San Diego) for the tdTomato plasmid; Rebecca Sager and Ryan Curl for help in neuron tracing and quantification; Diana Norman for aid in data visualization; Judson Belmont and Tina Lupone for technical support and animal management; Peter Calvert, Brian Howell, and Rick Matthews for comments and suggestions regarding the experiments, data analysis, and data visualization/presentation; and Robert Quinn and the staff in the Department of Laboratory Animal Resources for animal care.

The authors declare no competing financial interests.
1904). The dendrite is a distinct cellular compartment (Dotti and Simons, 1990; Yuste et al., 1994; Jareb and Banker, 1998) with morphological and synaptic properties that are essential for neuronal function. Unsurprisingly, mutations or toxins that disrupt dendritic development are associated with intellectual disability (Schapiro et al., 1984; Armstrong et al., 1998) and perhaps autism (Krey et al., 2013).

Both intrinsic and extrinsic mechanisms contribute to the appropriate development of dendrites (McAllister, 2002; Jan and

\section{This article is freely available online through the $J$ Neurosci Author Open Choice option.}

Correspondence should be addressed to Eric C. Olson, PhD, Department of Neuroscience and Physiology, SUNY Upstate Medical University, 750 East Adams Street, Syracuse, NY 13210. E-mail: olsone@upstate.edu.

DOl:10.1523/JNEUROSCI.1629-15.2015

Copyright $\odot 20150$ 0'Dell et al.

This is an Open Access article distributed under the terms of the Creative Commons Attribution License Creative Commons Attribution 4.0 International, which permits unrestricted use, distribution and reproduction in any medium provided that the original work is properly attributed. 
Jan, 2003; Van Aelst and Cline, 2004). Intrinsic mechanisms of dendritogenesis often relate to specification of cell identity and some transcription factors are known to dictate the overall size and branching complexity of the dendritic arbor (Puram and Bonni, 2013). Concurrently, extrinsic cues, both diffuse (Polleux et al., 2000; Niu et al., 2004; Dijkhuizen and Ghosh, 2005) and cell associated (Demyanenko et al., 2010), spatially shape arbor growth and its ultimate association with presynaptic elements (Tavosanis, 2012).

For some cortical excitatory neurons, the axon is known to emerge while the neuron is migrating through the cortical intermediate zone (i.e., future white matter; Schwartz et al., 1991; Hatanaka and Yamauchi, 2013; Sakakibara et al., 2014). The cellular origin of the apical dendrite, however, is not well understood. Based on analyses of fixed tissue preparations, the cortical neuron's apical dendrite has been hypothesized to emerge de novo from the neuronal somata (Ramon y Cajal, 1904) or by direct transformation of the leading process (Pinto-Lord et al., 1982; Hatanaka and Murakami, 2002; Olson et al., 2006; Chai et al., 2014). However, a detailed description of the initiation and growth kinetics of the cortical apical dendrite, and by extension knowledge of the underlying mechanisms, is lacking.

Reelin is a secreted protein known to influence both neuronal migration and dendritic growth. Reelin is highly expressed by Cajal-Retzius (CR) cells at the marginal zone (MZ), the outermost layer of the developing cortex (D'Arcangelo et al., 1995; Hirotsune et al., 1995; Ogawa et al., 1995). Migrating cortical neurons thus encounter high concentrations of secreted Reelin at the end of their migration route. In both mice (Caviness and Sidman, 1973) and humans (Hong et al., 2000), Reelin deficiency causes severe cortical dysmorphism characterized by inappropriately positioned neurons (Caviness and Sidman, 1973) and disrupted dendritic architecture (Goffinet, 1979; Pinto Lord and Caviness, 1979). In addition to mental retardation and mild epilepsy, patients with Reelin deficiency experience severe ataxia (Hourihane et al., 1993; Hong et al., 2000). Genetic studies have recently linked rare alleles of RELN to autism (De Rubeis et al., 2014; Wang et al., 2014).

Several specific cellular functions relevant to the end-stage of cortical neuron migration have been attributed to Reelin signaling: translocation (Olson et al., 2006; Franco et al., 2011; Sekine et al., 2012), detachment from radial glia fibers (Pinto-Lord et al., 1982; Dulabon et al., 2000; Hatanaka and Murakami, 2002; Sanada et al., 2004; Olson et al., 2006; Cooper, 2008), migration arrest (Pinto-Lord et al., 1982; Sheppard and Pearlman, 1997; Dulabon et al., 2000), and enhancement of apical dendritic growth (Goffinet and Lyon, 1979; Pinto Lord and Caviness, 1979; Niu et al., 2004; Matsuki et al., 2010; Nichols and Olson, 2010; O'Dell et al., 2012; Chai et al., 2014).

Direct visualization of the nascent dendritic arbor as cortical neurons transition from migrating to differentiating phenotypes could aid in the description of initial dendrite formation, the determination of how Reelin signaling affects that process, and the resolution of potentially competing models of Reelin function. To those ends, we used multiphoton time-lapse imaging applied to a whole hemisphere brain explant system (Nichols and Olson, 2010; O'Dell et al., 2012; Nichols et al., 2013) to determine the origin of the apical dendrite and the role(s) of Reelin signaling in coordinating the transition between migration and dendritogenesis for cortical neurons.

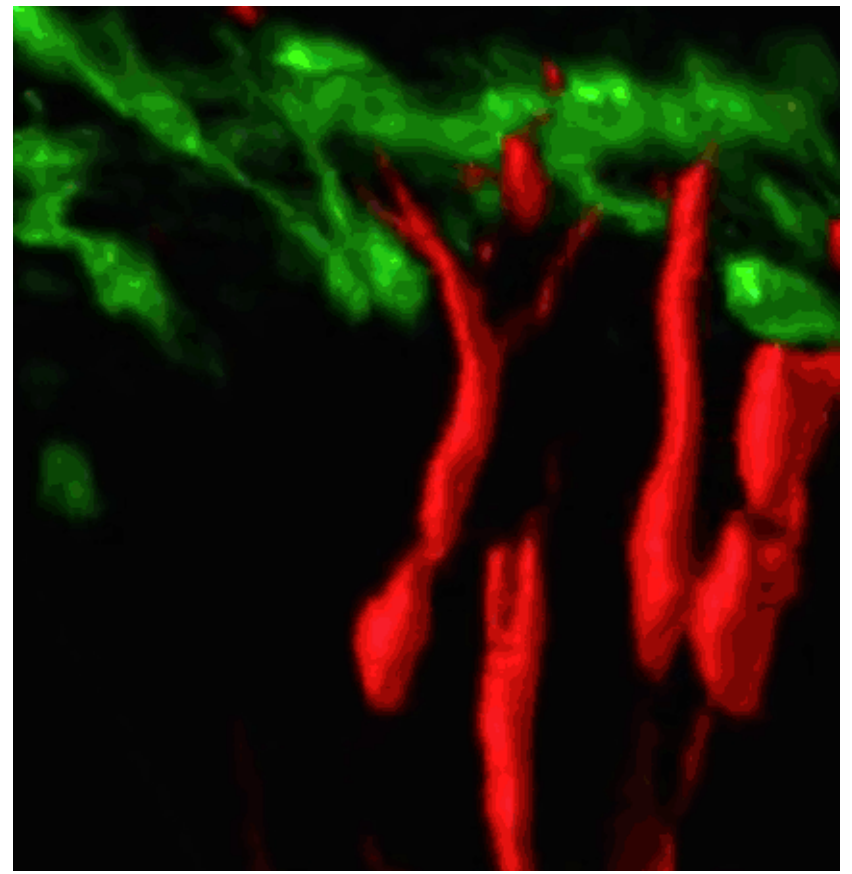

Movie 1. Migrating and differentiating deep layer neurons in a WT Pde1C explant. Timelapse imaging of WT explants revealed both actively translocating and postmigratory tdTomato $^{+}$early born cortical neurons in cortical explants derived from Pde1C::eGFP transgenic embryos. In these explants, the eGFP-expressing CR cells (green) are found in the MZ/SPP and migrating and differentiating deep layer neurons (red) are found in the developing CP. Actively translocating neurons first extend a sparsely branched leading process into the MZ/SPP. This was followed by rapid somal translocation and simultaneous elaboration of the dendritic arbor (Cell 1). Conversely, the somata of postmigratory neurons were localized just beneath the MZ/SPP and demonstrated a highly branched dendritic arbor that grew into the overlying $\mathrm{MZ} / \mathrm{SPP}$ throughout the imaging period (Cell 2). $z$-series were acquired at 10 min intervals for $4 \mathrm{~h}(0-240 \mathrm{~min})$. Time bar in lower left corner denotes the time of acquisition. Scale bars: 50 $\mu \mathrm{m}$ in whole dataset, $20 \mu \mathrm{m}$ in individually cropped ROls. Pde1C, Phosphodiesterase $1 \mathrm{C}$.

\section{Materials and Methods}

Mice. All animal protocols were reviewed and approved by the Institutional Animal Care and Use Committee of SUNY Upstate Medical University. reeler (B6C3Fe a/a-Reln; Jackson Laboratories) heterozygote mice were mated to produce the reeler (rlr) mutant embryos of either sex used for the described experiments. The $\mathrm{Tg}$ (Pde1C::eGFP)S45Gsat (GENSAT Project, National Institute of Neurological Disorders and Stroke-National Institutes of Health and The Rockefeller University) mouse line that expresses EGFP in preplate-derived neurons (Osheroff and Hatten, 2009) were crossed into the reeler line for some experiments. Data from WT $(+/+)$ and heterozygote $(+/-)$ embryos were combined and designated as WT (WT). Embryonic day 0 (E0) was designated as the day of plug discovery.

Explant cultures. Preparation of ex utero explant cultures was performed as described previously (Nichols et al., 2013). Briefly, E13 embryos were electroporated ex utero with $0.33 \mathrm{mg} / \mathrm{ml}$ of a pCAG-eGFP (Matsuda and Cepko, 2004) or pCAG-tdTomato construct and liveimaged 2 d later on E15. tdTomato cDNA (Shaner et al., 2004), a gift from Dr. Roger Tsien (University of California, San Diego), was cloned into the CAG promoter (Miyazaki et al., 1989) expression construct (Matsuda and Cepko, 2004). For fixed tissue high-resolution imaging of neuriteaxon interactions in the MZ/SPP, E13 explants were electroporated with $0.33 \mathrm{mg} / \mathrm{ml}$ of pCAGGS-mRFP (gift from Dr. Teiichi Furuichi) and fixed $2 \mathrm{~d}$ later at E15. Explants were cultured medial side down on $3 \mu \mathrm{m}$ pore size collagen-coated polytetrafluoroethylene filters (Transwell-COL; Corning) in DMEM-F12 medium plus GlutaMAX and supplemented with $1 \% \mathrm{G} 5,2 \% \mathrm{~B} 27$, and $1 \times$ penicillin and maintained in a high oxygen environment $\left(95 \% \mathrm{O}_{2} / 5 \% \mathrm{CO}_{2}\right)$ at $37^{\circ} \mathrm{C}$ for $\sim 48 \mathrm{~h}$ before imaging or fixation. All cell culture reagents were from Invitrogen. 
A
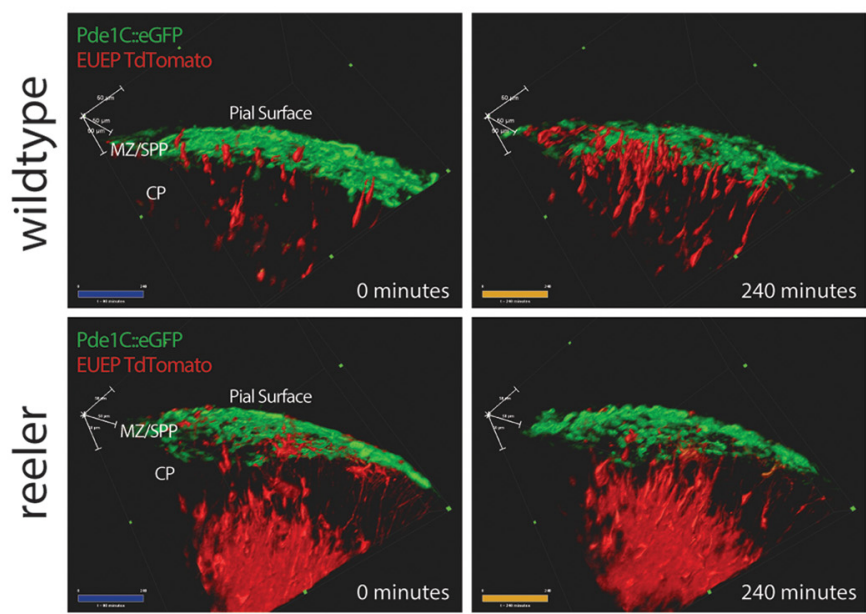

C

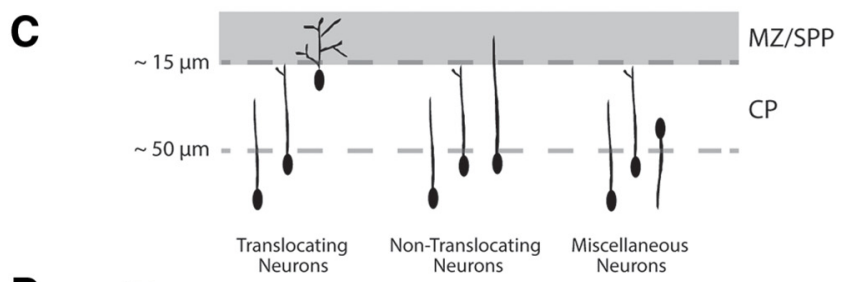

D

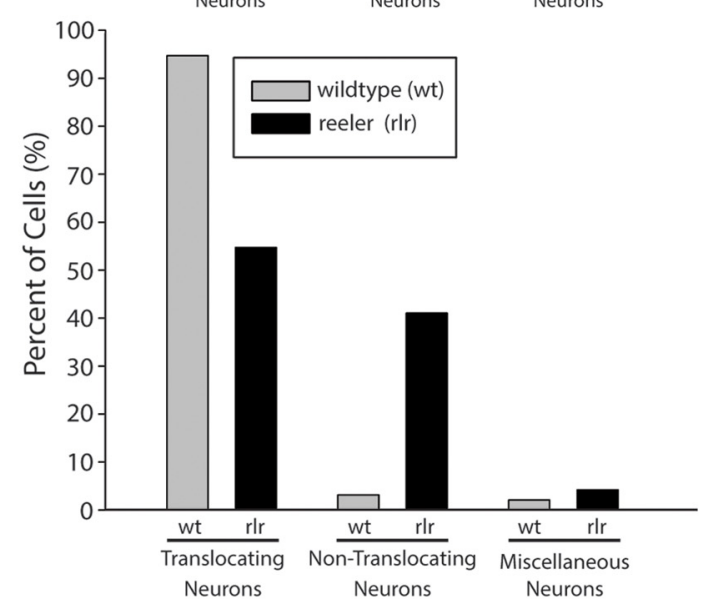

B

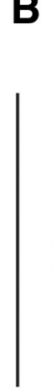




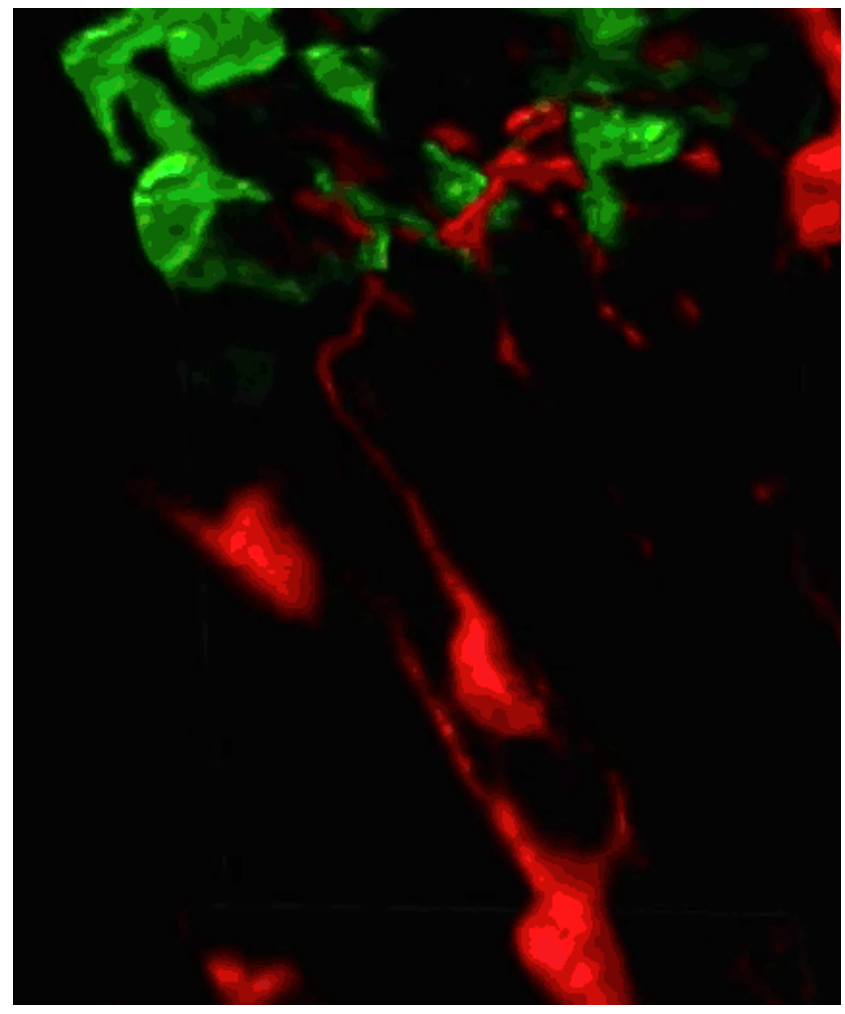

Movie 2. Migrating and differentiating deep layer neurons in a reeler Pde1C explant. Timelapse imaging of rlr explants revealed both actively translocating and postmigratory early born cortical neurons. The actively translocating neurons behaved like WT neurons during translocation, but demonstrated significant arbor collapse and MZ/SPP avoidance during the immediate posttranslocation period (Cell 1). Neurons that failed to translocate ( $\sim 41 \%$ of neurons in reeler explants) showed highly branched arbors that grew below the MZ/SPP. In some cases, these neurons established neurite contact with the MZ/SPP for brief periods that were followed by retraction (Cell 2). In addition, some neurons showed leading process collapse during translocation (Cells 3 and 4). Postmigratory neurons were usually multipolar and tangentially oriented below the MZ/SPP. These cells had highly dynamic and sparsely branched arbors that largely avoided the overlying MZ/SPP throughout the imaging period (Cell 5). $z$-series were acquired at $10 \mathrm{~min}$ intervals for $4 \mathrm{~h}(0-240 \mathrm{~min})$. Time bar in lower left corner denotes the time of acquisition. Scale bars: $50 \mu \mathrm{m}$ in whole dataset, $20 \mu \mathrm{m}$ in individually cropped R0ls. Pde1C, Phosphodiesterase $1 C$.

and sectioned at $100 \mu \mathrm{m}$ using a vibratome. Floating sections were sequentially incubated overnight with primary and secondary antibodies diluted in PBS (with 0.5\% Triton X-100 and 2\% BSA). Anti-Smi312 (1:1000; Covance), anti-rat-401 (nestin; 1:50; Developmental Studies Hybridoma Bank), and CR50 anti-Reelin (1:500; MBL) were used. Alexa Fluor 488-conjugated IgG (1:500; Invitrogen) and Alexa Fluor 555conjugated IgG (1:500; Invitrogen) secondary antibodies were used and Hoechst 33342 ( $2 \mu \mathrm{g} / \mathrm{ml}$; Invitrogen) was used to counterstain nuclei.

Western blot analysis. Before lysis, whole hemisphere explants were gently washed in ice-cold Hank's balanced salt solution to remove residual exogenous Rln-CM that may have adhered to the external surface of the meninges during bath application/live imaging. Explants were then lysed in cold RIPA buffer (20 mM Tris, pH 7.5, $150 \mathrm{~mm} \mathrm{NaCl,} 1.0 \%$ Nonidet P-40, 0.05\% sodium deoxycholate, $1.0 \mathrm{~mm}$ EDTA, and $0.10 \%$ SDS supplemented with $1.0 \mathrm{~mm}$ sodium orthovanadate, $20 \mathrm{~mm}$ sodium fluoride, and a protease inhibitor mixture [P-8340; Sigma]) and proteins were separated by SDS-PAGE and immunoblotted as described previously (Powrozek and Olson, 2012). Anti-Reelin (aa 164-496, clone G10, 1:500; Millipore) and anti- $\alpha$ tubulin (B512, 1:2000; Sigma) primary antibodies were used. Membranes were incubated with a horseradish peroxidase (HRP)-linked anti-mouse secondary antibody (1:10,000; Bio-Rad) and visualized using chemiluminescence (Supersignal WestPico; Thermo Fisher Scientific) detected by Kodak Biomax XAR film. As a loading control, membranes were stripped (62.5 mm Tris- $\mathrm{HCl}, 2.0 \%$
SDS, $10 \mu \mathrm{M} \beta$-mercaptoethanol) for $30 \mathrm{~min}$ at $50^{\circ} \mathrm{C}$ and reprobed with anti- $\alpha$ tubulin antibody.

Multiphoton live imaging. Explants were maintained under continuous superfusion with oxygenated medium warmed by a SH7B inline heater (Warner Instruments). Live imaging was performed on an upright Thorlabs Accera Series 2-channel multiphoton microscope coupled to a Chameleon Multiphoton Ti:Sapphire tunable laser for excitation (Coherent). Detection was provided by two ultrasensitive GaAsP PMTs (Hamamatsu) with band pass 525/50 nm and 605/70 nm filter cubes (Chroma Technology) for green/red imaging, respectively. Images were collected with an Olympus XLUMPlanFLN $20 \times / 1.0$ water objective with a $2 \mathrm{~mm}$ working distance. Due to the geometry of the whole hemisphere explant, the neurons in the dorsomedial cortex migrate largely in the planar dimensions of the imaged field (Nichols et al., 2013). For eGFP visualization, an optimized wavelength of $880 \mathrm{~nm}$ was used, whereas a wavelength of $910 \mathrm{~nm}$ was used for explants expressing both tdTomato and eGFP. For all live imaging studies, $z$-series were collected every 10 min for up to $6 \mathrm{~h}$ at $1.0 \mu \mathrm{m} z$-intervals. Scanning was bidirectional with 10 frame averaging. A typical imaging field was $300 \times 300 \times 200 \mu \mathrm{m}$ with typical voxel dimensions of $0.293 \times 0.293 \times 1 \mu \mathrm{m}$.

Fixed tissue preparation and high-resolution confocal imaging. $z$-series were collected with a Zeiss LSM510 laser scanning confocal microscope (SUNY Upstate Medical University Center for Bioresearch Imaging). Tissue sections were mounted in 90\% glycerol/20 mM Tris/0.5\% $N$-propylgallate and sealed under $0.17 \mathrm{~mm}$ glass coverslips $(22 \times 50 \mathrm{~mm}$, No.1; VWR). Images were collected using a 40×/1.3 Plan-NeoFluar oilimmersion objective at $0.2 \mu \mathrm{m} z$-step intervals with lateral pixel dimensions of $0.11 \mu \mathrm{m}$. Immersion oil used had a refractive index of 1.518 (Carl Zeiss). Using the FIJI plugin MetroloJ, experimental point spread functions and full-width at half maximum (i.e., system resolution) in both the lateral and axial planes were calculated using subresolution, $200 \mathrm{~nm}$ red (560/580 nm)-green (505/515 nm) fluorescent beads (TetraSpeck Fluorescent Microspheres Size Kit; Invitrogen). Subresolution beads were imaged using the same image acquisition parameters as were used to collect $z$-series for high-resolution neurite-axon interaction analysis.

Analysis of neurite arbor dynamics in translocating and postmigratory neurons. All images were imported into FIJI (www.fiji.sc), an open source distribution of Image J. Stacks were registered as 4D hyperstacks $(x, y, z$, and time) using the open source Correct 3D Drift plugin in the FIJI package. Individual translocating and postmigratory neurons and their full neurite arbors were traced at all time points using the open source Simple Neurite Tracer plugin in the FIJI package (Longair et al., 2011). $3 \mathrm{D}$ reconstructed orthoslices and 4D movies were made using Amira 3D Software for Life Sciences (FEI). Distance below the pial surface, total apical arbor size, and total apical branch number were measured at each time point from the registered and hyperstacked skeletonized traces. For translocating neurons, only well isolated cells with soma $>65 \mu \mathrm{m}$ below the pia and with leading process that contacted the MZ/SPP during the first hour of the $4 \mathrm{~h}$ imaging period were analyzed. For postmigratory neurons, only neurons that met three preestablished criteria were included for tracing: (1) presence of a fully translocated soma within $50 \mu \mathrm{m}$ of the overlying MZ/SPP identified at the first image acquisition, (2) no movement of the neuron or its arbor out of the xyz frame of imaging over all time points, and (3) an easily identifiable and traceable neurite arbor over all time points. Neurite extension and retraction velocities were determined for all traced cells on a per neurite basis for each $10 \mathrm{~min}$ acquisition interval.

Analysis of dendrite-axon contact. All images were imported into FIJI software. Analysis of subresolution, $200 \mathrm{~nm}$ red (560/580 nm)-green (505/515 nm) fluorescent beads (TetraSpeck Fluorescent Microspheres Size Kit; Invitrogen) revealed a registration error between the red and green channels that was corrected with the application of a $-1.0,-2.0(x$, $y)$ pixel translation on the green channel. This corrective translation was applied to all $z$-series before analysis. To assess the interactions between developing neurites of postmigratory neurons and CR cell axons, a FIJI macro was developed that converted the red and green channel to binary images after Otsu thresholding. A median filter of a 1 pixel radius was then applied to remove noise while preserving edges. The number of overlapping pixels between the two channels was calculated in each 
A
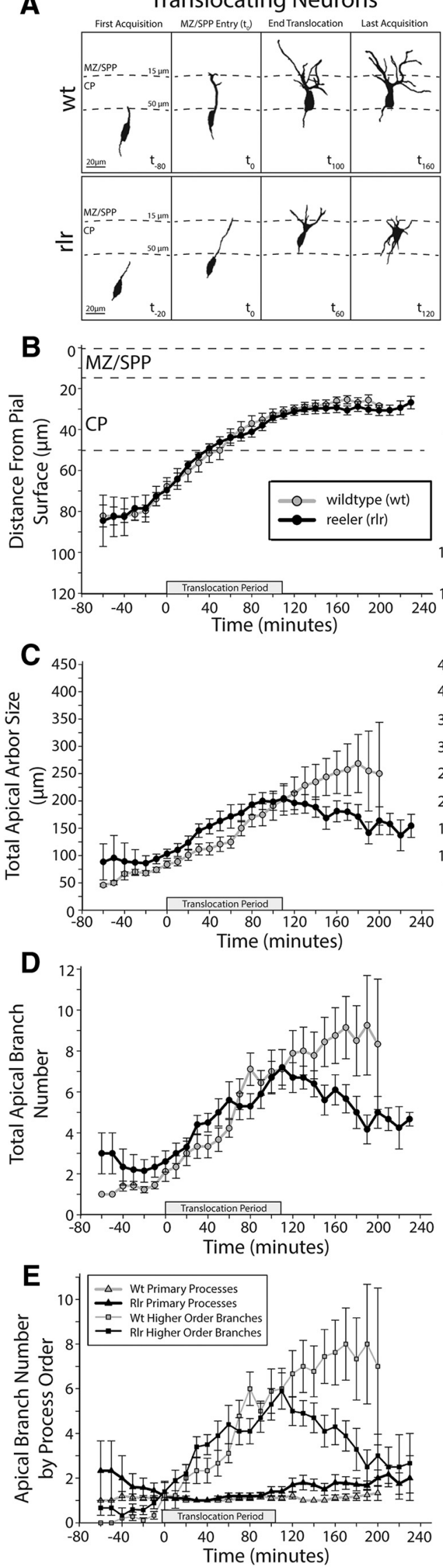

Non-Translocating Neurons
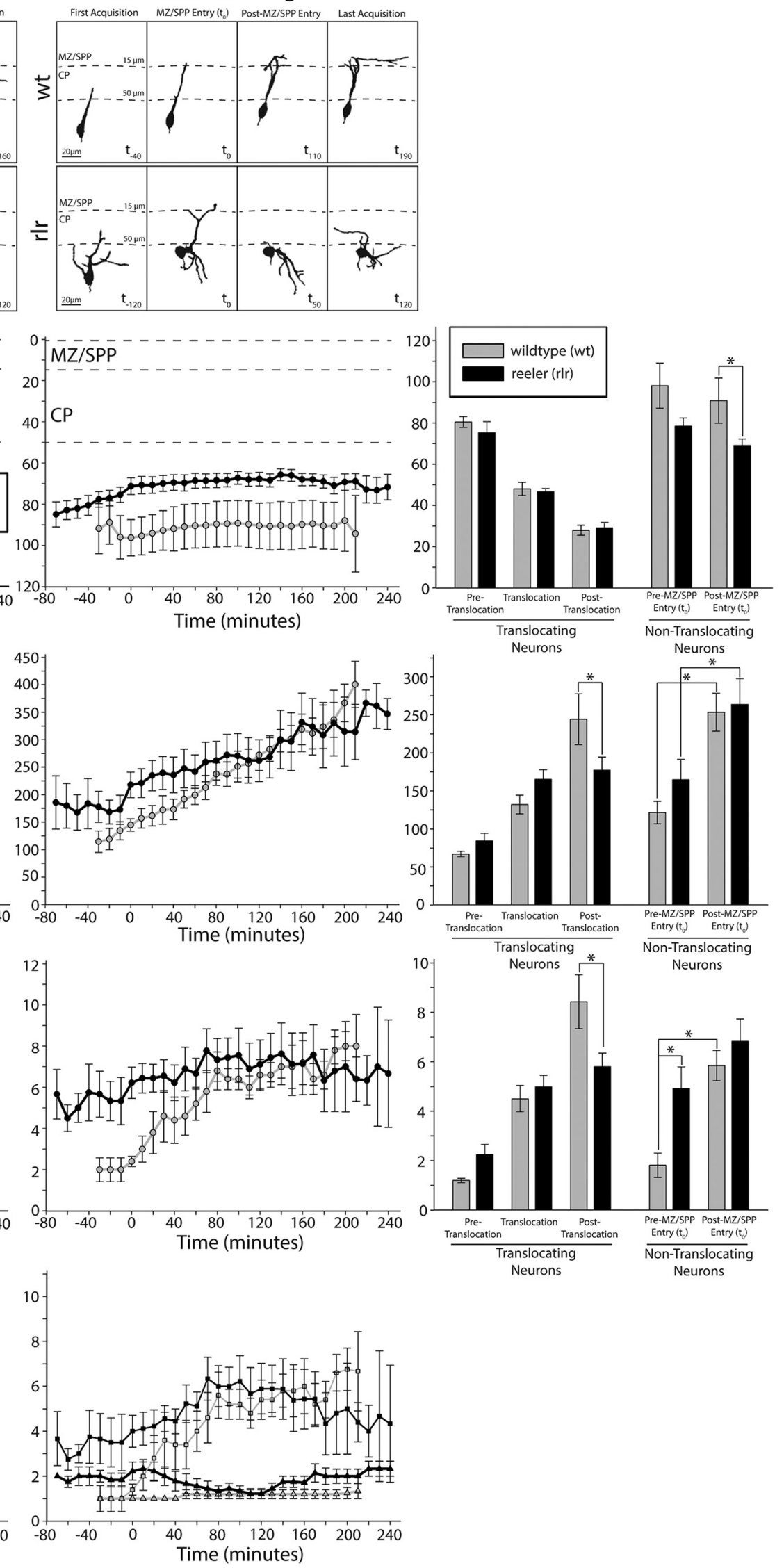

Figure 2. Leading process growth and branching is disrupted in reeler cortices. $A$, Representations of flattened (z-projected) translocating and nontranslocating neurons in WT and rlr explants. $\boldsymbol{B}-\boldsymbol{D}$, Quantification of somal positioning and neurite morphology of translocating WT and rlr neurons after leading process contact with the M/SPP $\left(t_{0}\right)$. (Figure legend continues.) 
Table 1. Higher neurite extension and retraction velocities and more frequent retraction events in reeler cortices

\begin{tabular}{|c|c|c|c|c|c|c|}
\hline & $\begin{array}{l}\text { Neurite extension } \\
\text { velocities ( } \mu \mathrm{m} / \mathrm{min})\end{array}$ & $\begin{array}{l}\text { Neurite retraction } \\
\text { velocities }(\mu \mathrm{m} / \mathrm{min})\end{array}$ & $\begin{array}{l}\text { Extension events (\%) } \\
\text { (events observed) }\end{array}$ & $\begin{array}{l}\text { Retraction events (\%) } \\
\text { (events observed) }\end{array}$ & $\begin{array}{l}\text { Total arbor } \\
\text { growth }(\mu \mathrm{m})\end{array}$ & $\begin{array}{l}\text { Arbor growth } \\
\text { rate }(\mu \mathrm{m} / \mathrm{h})\end{array}$ \\
\hline \multicolumn{7}{|l|}{ Translocation period } \\
\hline \multicolumn{7}{|l|}{ Translocating neurons } \\
\hline $\operatorname{rlr}(n=10$ cells $)$ & $0.98 \pm 0.03^{*}$ & $-0.85 \pm 0.04(p=0.065)$ & $53.5 \pm 1.4^{*}+(41.2 \pm 5.4)$ & $46.5 \pm 1.4^{*}+(35.4 \pm 4.9)$ & $101.9 \pm 20.6$ & $52.2 \pm 12.1 \dagger$ \\
\hline \multicolumn{7}{|c|}{ Immediate posttranslocation period } \\
\hline \multicolumn{7}{|c|}{ Translocating neurons } \\
\hline \multicolumn{7}{|l|}{ After MZ/SPP entry $\left(t_{0}\right)$} \\
\hline \multicolumn{7}{|c|}{ Nontranslocating neurons } \\
\hline WT ( $n=5$ cells) & $0.74 \pm 0.04$ & $-0.66 \pm 0.03$ & $56.8 \pm 1.3(84.6 \pm 11.1)$ & $43.2 \pm 1.3(66.2 \pm 12.1)$ & $196.8 \pm 26.7$ & $55.6 \pm 6.5$ \\
\hline $\operatorname{rlr}(n=9$ cells $)$ & $0.86 \pm 0.05(p=0.058)$ & $-0.86 \pm 0.03^{*}$ & $51.0 \pm 0.7^{*}(82.2 \pm 15.0)$ & $49.0 \pm 0.7^{*}(79.2 \pm 14.1)$ & $38.8 \pm 11.4$ & $11.4 \pm 6.6^{*}$ \\
\hline
\end{tabular}

Extension and retraction velocities of all neurites for each cell were quantified throughout the imaging period. Rlr neurites showed higher extension and retraction speeds than WT in all conditions. Rlr neurites also demonstrated a greater numbers of retraction events than WT, particularly in the immediate posttranslocation period. These differences produced the lower arbor growth rate observed with rlr neurons during translocation and overall arbor retraction during the posttranslocation period. Error bars denote SEM. Three-way ANOVA with post hoc Holm-Sidak pairwise multiple comparison procedures were performed between genotypes, extension/retraction events, and different phases of translocation on a per cell basis. Any significant effects and/or interactions were further analyzed by two-way ANOVA with post hoc Holm-Sidak comparison procedures.

${ }^{*} p<0.05$ compared with WT controls within the same translocation period.

$t p<0.05$ denoting a significant difference between the translocation and posttranslocation period of the same genotype. Quantitative analysis was run on the same traced data sets presented in Figure 2.

$z$-slice and summed for the entire $z$-series. Areas containing pixels with above threshold green and red signal were referred to as "candidate contact areas" (CCAs) because they represented regions in which the axons and dendrites could not be spatially resolved. The areas were expressed as a percentage of the total available neurite arbor (red channel) and referred to as "percent neurite overlap." To determine whether CCAs were the result of random growth into the CR cell axonal plexus, a Shuffle Slices macro was applied to the $z$-stack of the neurite arbor (red) channel. The new "shuffled" neurite arbor was then merged back into the properly ordered (nonshuffled) axon (green) channel. The newly created twochannel image was then analyzed for CCAs. 3D reconstructions of CCAs were made using the open source 3D Viewer plugin in the FIJI package.

Statistical analyses. For all dynamic neurite morphology measurements, one-, two-, or three-way ANOVA with post hoc Holm-Sidak pairwise multiple-comparison procedures were run using the SigmaPlot package (Systat) to determine significance.

\section{Results}

Translocation is characterized by the rapid, continuous movement of the neuronal somata during the final stage of cortical migration (Nadarajah et al., 2001). To determine the relationship between translocation and the initiation of the apical neurite arbor, neurons with leading process that entered a zone extending

\section{$\leftarrow$}

(Figure legend continued.) WT and rlr translocating neurons demonstrated similar translocation speed $(\boldsymbol{B})$, arbor growth $(\boldsymbol{C})$, and branch number increases $(\boldsymbol{D}, \boldsymbol{E})$ during the phases of pretranslocation and translocation and were characterized by a single, apically oriented primary process $(\boldsymbol{E})$. During the immediate posttranslocation phase, however, WT arbors continued to branch from the single primary process into the overlying MZ/SPP, whereas rlr neurons collapsed and avoided the MZ/SPP, displaying significant increases in primary processes (i.e., multipolar) coupled with significant decreases in higher order branching $(\boldsymbol{E})$. Interestingly, the pretranslocation phase of rlr neurons was characterized by an elevated number of primary process number (compared with WT controls), but these extra primaries were successfully retracted before the start of translocation $(\boldsymbol{E})$. Nontranslocating WT and rlr neurons displayed larger and more highly branched, multipolar arbors than translocating neurons $(\boldsymbol{B}-\boldsymbol{E})$. These neurons showed abnormal arbor growth typically localized below the MZ/SPP. Dashed lines represent the lower boundary of the MZ/SPP $(\sim 15 \mu \mathrm{m})$ and $C P(\sim 50 \mu \mathrm{m})$ in $\boldsymbol{A}$ and $\boldsymbol{B}$. Error bars denote SEM. Dashed lines represent the pial surface in $\boldsymbol{D}$. Two-way ANOVA with post hoc Holm-Sidak pairwise multiple-comparison procedures were performed between genotypes and different phases of translocation on a per cell basis. ${ }^{*} p<0.05$ compared with WT controls. Translocating WT analysis: 9 neurons from 8 explants across 8 litters. Translocating rlr analysis: 10 neurons from 8 explants across 8 litters. Nontranslocating WT analysis: 4 neurons from 4 explants across 4 litters. Nontranslocating rlr analysis: 9 neurons from 4 explants across 4 litters. Scale bars in $A$ and $D, 20 \mu \mathrm{m}$.
$15 \mu \mathrm{m}$ underneath the pial surface during the first hour of a $4 \mathrm{~h}$ imaging period were selected for quantitative analysis (Fig. 1C; see Materials and Methods). The selection process excludes from analysis of both multipolar neurons (Tabata and Nakajima, 2003) and locomoting neurons (Nadarajah et al., 2001) that are found at deeper positions in the developing cortex. This $15 \mu \mathrm{m}$ zone approximately corresponds to the MZ in WT cortices and the superplate (SPP) in reeler mutant cortices (Caviness, 1982; Sheppard and Pearlman, 1997; O'Dell et al., 2012). A total of 190 neurons in WT and reeler explants were examined and placed into two primary categories on successful or failed translocation during the subsequent $3 \mathrm{~h}$ imaging period (Fig. $1 C, D$ ). A third, miscellaneous category was included for cells not readily classified (e.g., neurons that reversed migration direction).

In WT explants, $95 \%$ of neurons with a leading process that contacted the MZ/SPP successfully translocated during the subsequent $\sim 3 \mathrm{~h}$ imaging period (Fig. 1; Movie 1, cell 1). The leading processes of these neurons displayed dramatic increases in growth and branching into the overlying MZ during the translocation period. Notably, $55 \%$ of reeler neurons with a leading process that contacted the MZ/SPP also successfully translocated and simultaneously elaborated a branched arbor. However, in most cases the neurites of these translocating reeler neurons appeared to retract and reorganize away from the MZ/SPP after translocation was completed (Fig. 1; Movie 2, cell 1). Although 3\% of WT neurons that contacted the MZ/SPP did not translocate, $41 \%$ of such neurons in reeler explants failed to translocate, with the majority of those neurons not elaborating a branched neurite arbor into the MZ/SPP, or initiating an arbor that retracted before or during translocation (Fig. 1; Movie 2, cells 3 and 4). This initial analysis suggests 1 ) that translocation occurs simultaneous with dendritic arbor growth and branching, and 2) a common feature of migrating neurons in reeler cortices, whether they translocate (Movie 2, cell 1 and 2) or not (Movie 2, cell 3 and 4), is neurite retraction from the MZ/SPP.

To further characterize and quantify arbor differences between WT and reeler early born neurons, neurite arbors of 9 WT and 10 reeler translocating neurons were traced in 3D at each time point throughout the imaging period (see Materials and Methods). The distance between the soma and the pial surface, the total apical arbor size, and the total apical branch number were determined at each time point (Fig. $2 B-D$ ). To facilitate direct 
A

\section{Translocating Neurons}
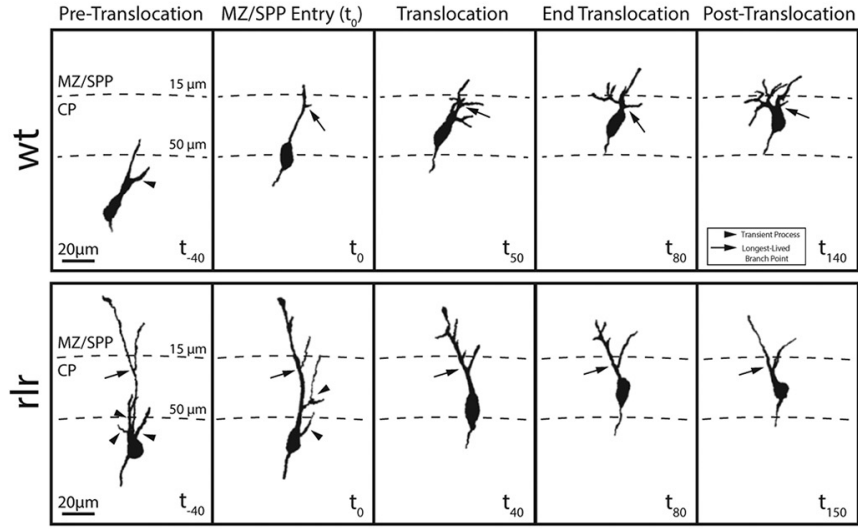

Non-Translocating Neurons
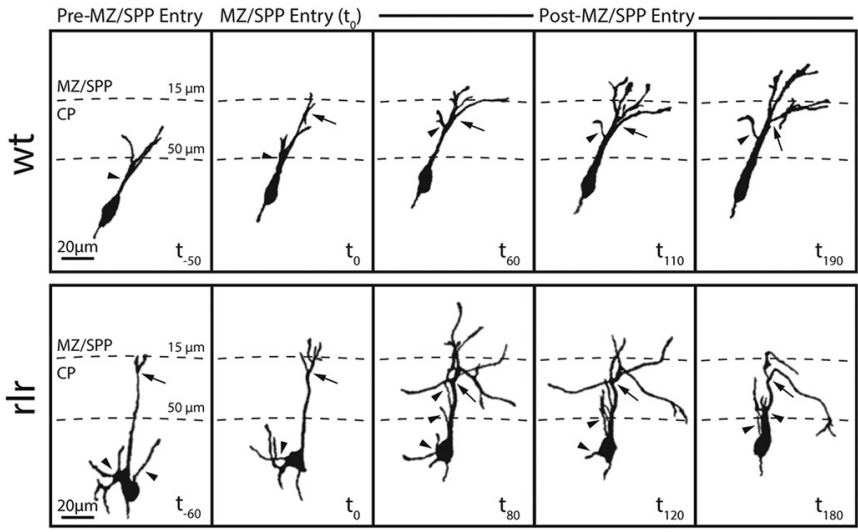

\section{B}

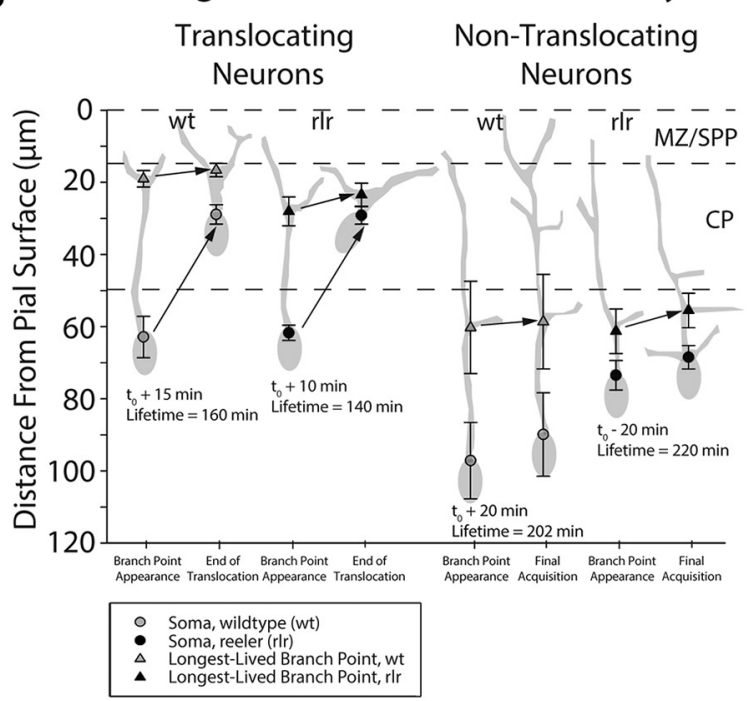

Figure 3. Correlation between long-lived neurite branch points and somata position. $\boldsymbol{A}$, Representations of flattened (z-projected) translocating and nontranslocating WT and rlr early born neurons. The arrow identifies the longest-lived branch point and arrowheads represent transient primary and secondary branches. In all translocating neurons, ectopic branches emanating from the primary neurite but below the MZ/SPP were successfully resolved before somal passage, with final somal arrest occurring within one cell diameter below the longest-lived branch point. Nontranslocating WT and rlr neurons displayed ectopic long-lived primary and secondary branches below the MZ/SPP that correlated with ectopic somal positioning. $\boldsymbol{B}$, Quantification of longestlived branch point and somal position during imaging period. In nontranslocating WT and rlr neurons, the longest-lived branch point was localized to significantly deeper positions below the pial surface (nontranslocating WT 58.6 and rlr $56.6 \mu \mathrm{m}$ ) than in successfully translocating WT and rlr neurons (translocating WT 16.0 and rlr $23.4 \mu \mathrm{m}, p<0.001$ ). Quantitative analysis was run on the same traced datasets presented in Figure 2. Dashed lines represent the lower boundaries of the MZ/SPP $(\sim 15 \mu \mathrm{m})$ and CP $(\sim 50 \mu \mathrm{m})$ in $\boldsymbol{A}$ and $\boldsymbol{B}$. Error bars denote SEM. Three-way ANOVA with post hoc Holm-Sidak pairwise multiple-comparison procedures were performed between genotypes, category of neuron (translocating and nontranslocating), and acquisition time point (branch point appearance and end of translocation) on a per cell basis. Scale bar in $A, 20 \mu \mathrm{m}$.

comparison between neurons, the time of leading process contact with the MZ/SPP was designated $t_{0}$ on a per cell basis, and all traces were aligned to this time point. For WT neurons, the total apical neurite arbor increased $240 \%$ in size (Fig. 2C) and $340 \%$ in branch number (Fig. 2D) in the $110 \mathrm{~min}$ translocation period following $t_{0}$. This substantial increase in arbor size and branching was initiated at the time of leading process contact with the MZ/ SPP and continued throughout and immediately after the translocation period (Fig. 2C,D; Movie 1, cell 1). In the subset of reeler neurons that successfully translocated (55\%; Fig. 1B), apical arbor growth increased $200 \%$ and branch number increased $280 \%$ during the translocation period, but total arbor size and branch number (both in and out of the MZ/SPP) declined 25\% and 35\% respectively during the immediate posttranslocation period (Fig. $2 C, D)$. Importantly, following translocation, it was the radially directed processes of these neurons that were lost, which often occurred simultaneously with the elaboration of multiple, tan- gentially oriented primary processes from the same cells (Fig. 2E; Movie 2, cell 1) (O'Dell et al., 2012). This analysis indicates that 1) dendritic growth and branching is initiated at the time the leading process contacts the MZ/SPP, 2) for the subset of reeler neurons that translocate, dendritic growth and branching as well as somal movements are quantitatively similar to WT, and 3) although reeler neurites project into the MZ/SPP, they become unstable and typically begin to retract and reorganize within minutes following translocation.

Based on observations from prior studies (Pinto-Lord et al., 1982; Olson et al., 2006; Franco et al., 2011; Sekine et al., 2012; Gil-Sanz et al., 2013), we hypothesized that nontranslocating neurons in reeler explants would retain a compact migration morphology. Surprisingly, both WT and reeler nontranslocating neurons that contacted the MZ/SPP were characterized by larger and more highly branched arbors than successfully translocating neurons at corresponding time points (Fig. 2C,D). The arbors of 

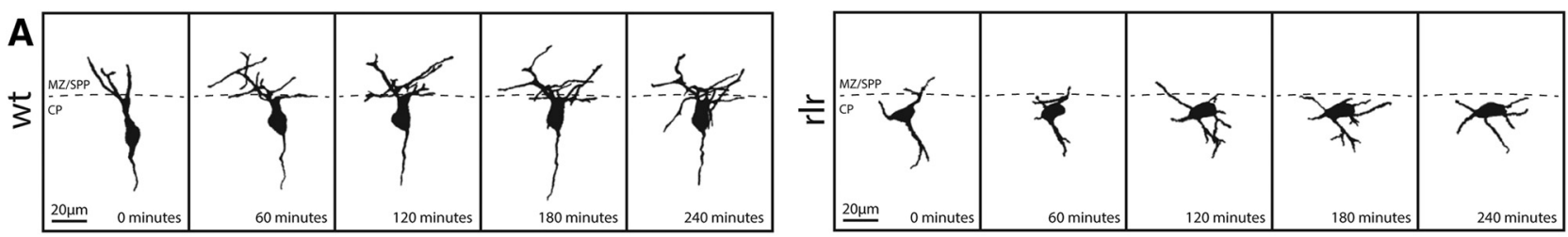

B
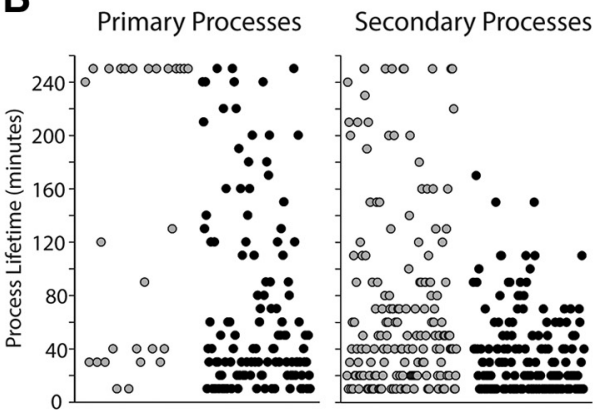

Tertiary Processes

Quaternary Processes

D

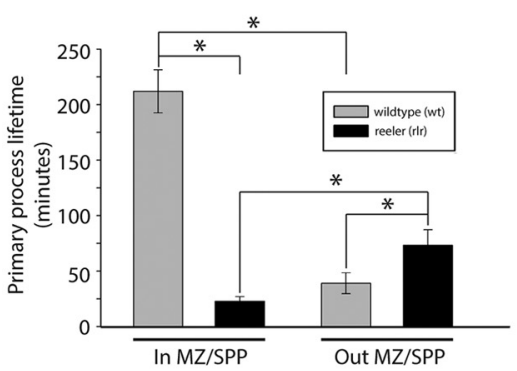

\section{G}

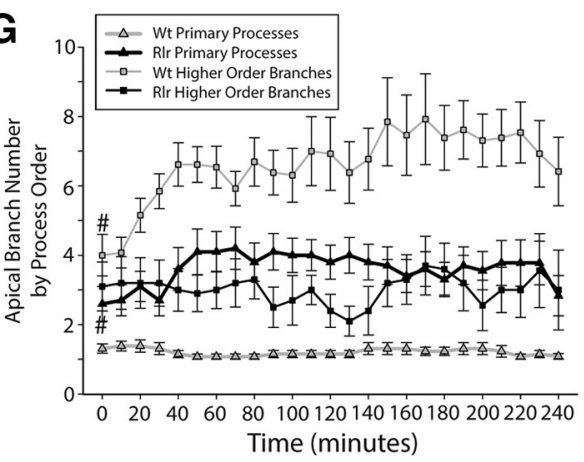

$\mathbf{E}$

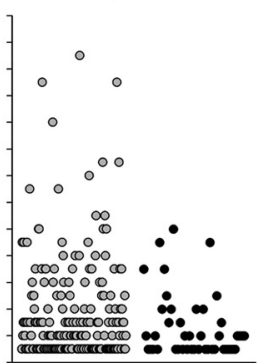

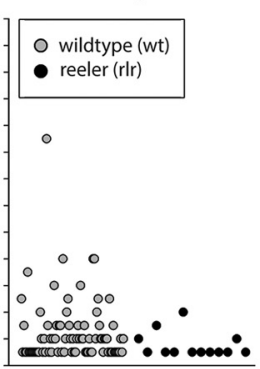

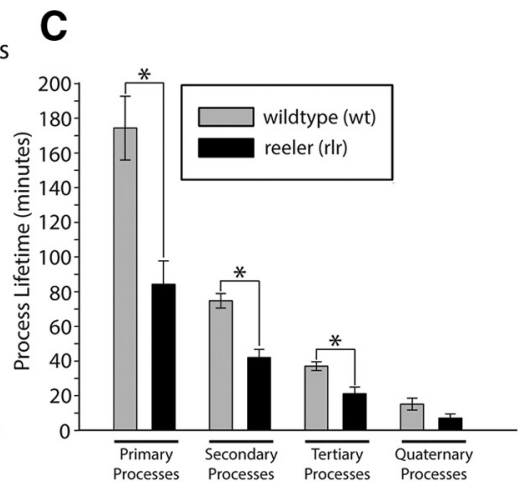

$\mathbf{F}$
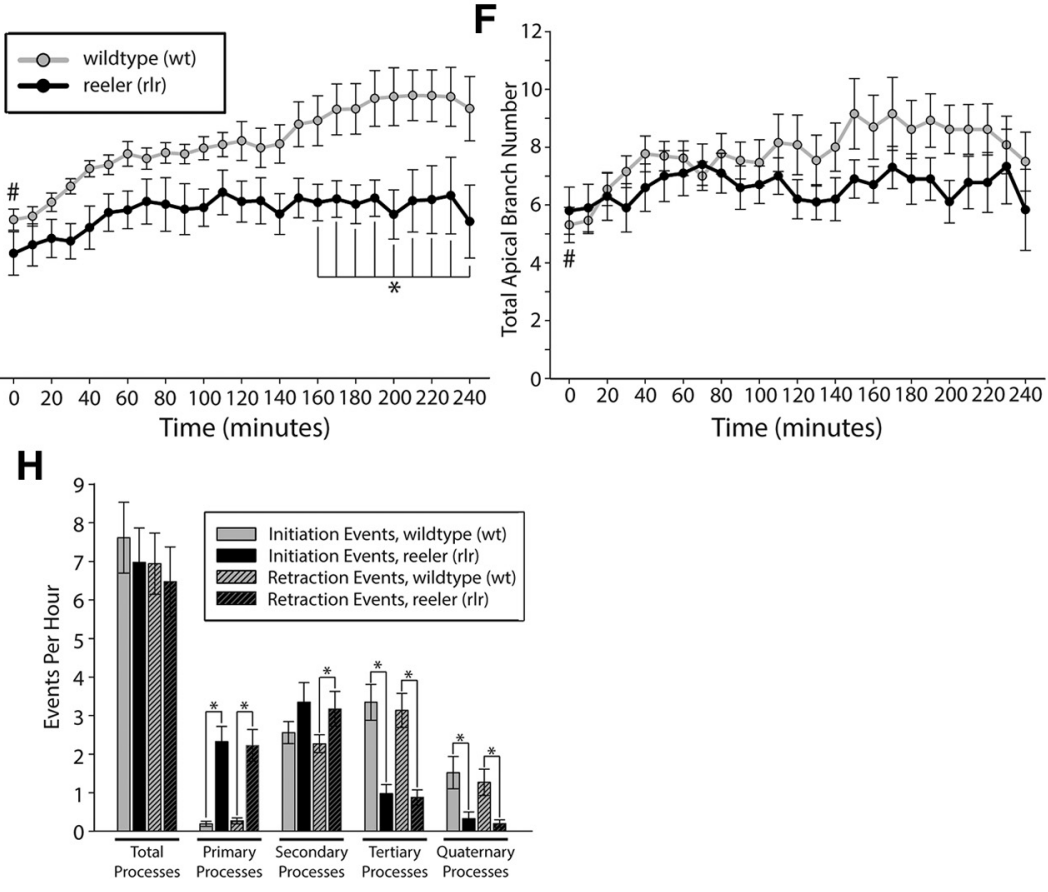

Figure 4. Postmigratory neurons show unstable neurites in reeler cortices. $A$, Representations of flattened ( $z$-projected) postmigratory neurons in WT and rlr explants during a $4 \mathrm{~h}$ imaging period. RIr neurons demonstrated multipolar morphologies and neurites that avoided the overlying MZ/SPP. B, Scatter plots of process lifetimes by branch order. C, Quantitative analysis on a per cell basis revealed significantly longer-lived primary, secondary, and tertiary processes in WT neurons with a prominent bimodal distribution of primary process lifetimes in the WT controls. $\boldsymbol{D}$, Primary processes of rlr neurons had significantly shorter lifetimes in the MZ/SPP compared with both WT controls and rlr primary processes outside of the MZ/SPP. Total apical arbor size (E) and branch number $(\boldsymbol{F})$ in WT neurons was observed to significantly increase over time, whereas rlr neurons only demonstrated slight but nonsignificant increases in arbor size and number. Although overall branch number was similar between WT and rlr arbors $(\boldsymbol{F})$, the distribution of that branching was very different across branch orders $(\boldsymbol{G})$. Rlr arbors demonstrated multipolar morphologies, characterized by more primary processes (interaction between genotype and time, $p=0.016$ ) and reduced higher-order branching (interaction between genotype and time, $p=0.039$ ) over time compared with WT controls. $\boldsymbol{H}$, No differences were observed in total neurite initiation or retractions per hour between genotypes, but rlr neurons displayed significantly more primary process initiation and retraction events per hour and fewer tertiary and quaternary initiation and retraction events per hour compared with WT controls. Dashed lines in $A$ represent the MZ-SPP/CP boundary. Error bars indicate SEM. For process lifetime analysis, two-way ANOVA with post hoc Holm-Sidak pairwise multiple-comparison procedures were performed on a per cell basis. For quantitative analysis of total apical arbor size and branch number, one- and two-way repeated-measures ANOVA with post hoc Holm-Sidak comparison procedures were performed over time. For analyses of initiation/retraction events by process order, three-way ANOVA with post hoc Holm-Sidak pairwise multiple-comparison procedures were performed on a per cell basis. * $p<$ 0.05 compared with WT controls; \#p <0.05, denoting a significant trend over time. WT analysis: 13 neurons from 10 explants across 10 litters. rlr analysis: 10 neurons from 6 explants across 6 litters. Scale bar in $A, 20 \mu \mathrm{m}$.

reeler nontranslocating neurons displayed multipolar morphologies and highly branched arbors localized at deeper positions on the leading process, and did not exhibit extensive growth into the overlying MZ/SPP (Fig. 2E; Movie 2, cells 3 and 4). In contrast, the rarely observed (3\%; Fig. $1 B$ ) WT nontranslocating neurons were characterized by bipolar morphologies and often had arbor growth into the MZ/SPP in addition to mislocalized arbor branching at deeper positions on the leading process (Fig. 2E). 
Table 2. Altered neurite dynamics of postmigratory neurons in reeler cortices

\begin{tabular}{|c|c|c|c|c|c|c|}
\hline & $\begin{array}{l}\text { Neurite extension } \\
\text { velocities }(\mu \mathrm{m} / \mathrm{min})\end{array}$ & $\begin{array}{l}\text { Neurite retraction } \\
\text { velocities }(\mu \mathrm{m} / \mathrm{min})\end{array}$ & $\begin{array}{l}\text { Extension events (\%) } \\
\text { (events observed) }\end{array}$ & $\begin{array}{l}\text { Retraction events (\%) } \\
\text { (events observed) }\end{array}$ & $\begin{array}{l}\text { Total arbor } \\
\text { growth }(\mu \mathrm{m})\end{array}$ & $\begin{array}{l}\text { Arbor growth } \\
\text { rate }(\mu \mathrm{m} / \mathrm{h})\end{array}$ \\
\hline \multicolumn{7}{|l|}{ Postmigratory neurons } \\
\hline WT ( $n=13$ cells) & $0.70 \pm 0.03$ & $-0.62 \pm 0.04$ & $50.9 \pm 1.3(113.5 \pm 11.6)$ & $49.1 \pm 1.3(108.8 \pm 9.1)$ & $109.9 \pm 28.7$ & $27.6 \pm 7.2$ \\
\hline
\end{tabular}

Quantitative analysis of neurite extension and retractions on a per cell basis revealed a trend toward faster neurite extension $(p=0.118)$ and significantly higher retraction velocities ( $p=0.036$ ) in rlr neurite arbors compared with WT controls. No significant differences in the proportion of extension or retraction events were observed between genotypes. Error bars denote SEM.

${ }^{*} p<0.05$ compared with WT controls. Quantitative analysis was run on the same traced data sets presented in Figure 4.

The arbors of nontranslocating reeler neurons were as large and branched as those of neurons that had successfully translocated, possibly indicating that the leading process had transformed into the nascent branched dendrite before migration termination. These analyses of translocating and nontranslocating neurons suggest that, whereas dendritic growth was tightly correlated with successful translocation, dendritic initiation and growth were not sufficient for successful translocation.

The initial period of dendritic arbor growth in both WT and reeler cortices was highly dynamic, with individual neurites displaying periods of rapid extension and retraction. Because radially oriented dendritic arbors largely retracted in reeler cortices, we hypothesized that reeler neurites would spend more time retracting and/or retract faster than their WT counterparts during and immediately after the translocation period (Table 1). Neurite velocities were calculated for each 10 min imaging interval and compared both during and after translocation (Table 1). During translocation, a significantly higher average velocity of extension $(+30 \%, p=0.011)$ and retraction $(-27 \%, p=0.065)$ was observed for reeler neurites compared with WT controls (Table 1). In addition, reeler neurites spent a greater percentage of the imaging period retracting compared with WT (47\% vs 39\%, $p<$ 0.001). Differences between reeler and WT neurite kinetics became more substantial during the immediate posttranslocation period: reeler neurites had higher average extension $(+31 \%, p=$ $0.016)$ and retraction $(-54 \%, p<0.001)$ velocities compared with WT. In addition, reeler neurites spent $54 \%$ of the imaging period retracting compared with $48 \%$ for WT neurites $(p=$ $0.009)$. These differences resulted in a similar arbor growth rate for reeler neurons (compared with WT) during translocation $(+52.2 \mathrm{vs}+64.2 \mu \mathrm{m} / \mathrm{h}, p=0.651$; Table 1$)$, but an overall neurite retraction for reeler arbors during the immediate posttranslocation period $(-63.2 \mathrm{vs}+22.3 \mu \mathrm{m} / \mathrm{h}, p=0.003$; Table 1). Similarly, compared with nontranslocating WT neurons, nontranslocating reeler neurons demonstrated faster neurite extension $(+16 \%, p=0.058)$ and retraction $(-30 \%, p=$ 0.003 ) velocities, as well as significantly reduced (but still positive) arbor growth rates $(+11.4 \mathrm{vs}+55.6 \mu \mathrm{m} / \mathrm{h}, p=0.003$; Table 1). Therefore, in reeler cortices, neurites have consistently elevated extension and retraction velocities and become biased toward more retraction events and higher retraction velocities soon after the completion of translocation.

Consistent with prior findings (Nadarajah et al., 2001), we observed that somal translocation paused "beneath" branch points in the leading process until one of the branches was retracted, after which time translocation continued in the direction of the remaining branch (Fig. 3A). Throughout hundreds of hours of recorded cortical development, and independently of Reelin signaling, neuronal somata were never observed to migrate past branch points. This observation suggests that the establishment of a stable, branched leading process may impede further somal movement structurally and could contribute to precise migration arrest (Olson et al., 2006; Chai et al., 2014). To explore this possibility in greater detail, we examined the dataset of traced translocating neurons $(n=9 \mathrm{WT}$ and 10 reeler $)$ with respect to leading process branch formation. For eight of these WT translocating neurons, the branch point formed in the leading process upon contact with the MZ/SPP was stable for the entire imaging period and anticipated the somal arrest position to within one cell diameter (Fig. $3 A, B$; Movie 1, cell 1 ). In contrast, only 4 of 10 reeler translocating neurons successfully established a stable branch point at the MZ-SPP/cortical plate (CP) border that persisted throughout the imaging period. After migration arrest, most translocating reeler neurons exhibited apical arbor collapse, including collapse of the "stable" branch point, and initiated multiple, tangentially oriented primary processes (Movie 2, cell 1 and 2). These observations suggest that the establishment of a stable and branched leading process at the MZ and $\mathrm{CP}$ boundary prevents further radial movement of the soma and that this precise branching event (and the correlated somal arrest) is often disrupted in reeler cortices.

For some migrating reeler neurons, excessive, ectopic branching at deeper positions on the leading process may contribute to translocation failure (Fig. $3 A, B$ ). Whereas successfully translocating reeler neurons typically possess two distal branches when the leading process contacts the MZ/SPP, nontranslocating reeler neurons typically had six branches (Fig. 2D). These branches were numerous and transient, appearing and disappearing throughout the imaging period. The high density of ectopic branches and multiple primary processes prevented the establishment of the unbranched leading process that is typically associated with successfully translocating cells. This suggests that, for some reeler neurons, the inability to resolve mislocalized apical dendritic branches may prevent or contribute to a disruption of terminal translocation. WT nontranslocating neurons were infrequent (3\%) and had morphologies distinct from the corresponding reeler neurons, with deeper somata positions, greater arbor growth within the overlying MZ/ SPP, and deep branches that also appeared to impede the progress of somal translocation (Fig. $3 A, B$ ).

To explore the specific consequences of Reelin deficiency on dendritic growth and stability subsequent to migration, the neurites of postmigratory L6 neurons with somata that were found $<50 \mu \mathrm{m}$ underneath the pial surface at the beginning of the imaging period were examined (Fig. 4). Neurite arbors of 13 WT and 10 reeler neurons were completely traced at each time point throughout a $4 \mathrm{~h}$ imaging period. Although the somata of postmigratory WT and reeler neurons were equivalently positioned, reeler neurites were tangentially oriented, simplified, and often not localized to the MZ/SPP (Fig. 4G). At the onset of imaging, the total apical arbor size was comparable between genotypes (Fig. 4E), consistent with our prior study (O'Dell et al., 2012). Similar to translocating reeler neurons, these postmigratory reeler neurites demonstrated higher extension $(+16 \%, p=0.139)$ and retraction $(-23 \%, p=0.035)$ velocities compared with WT controls (Table 2). WT and reeler neurites spent a similar percentage of the imaging period retracting ( $51 \%$ vs $49 \%, p=0.842$ ), leading 


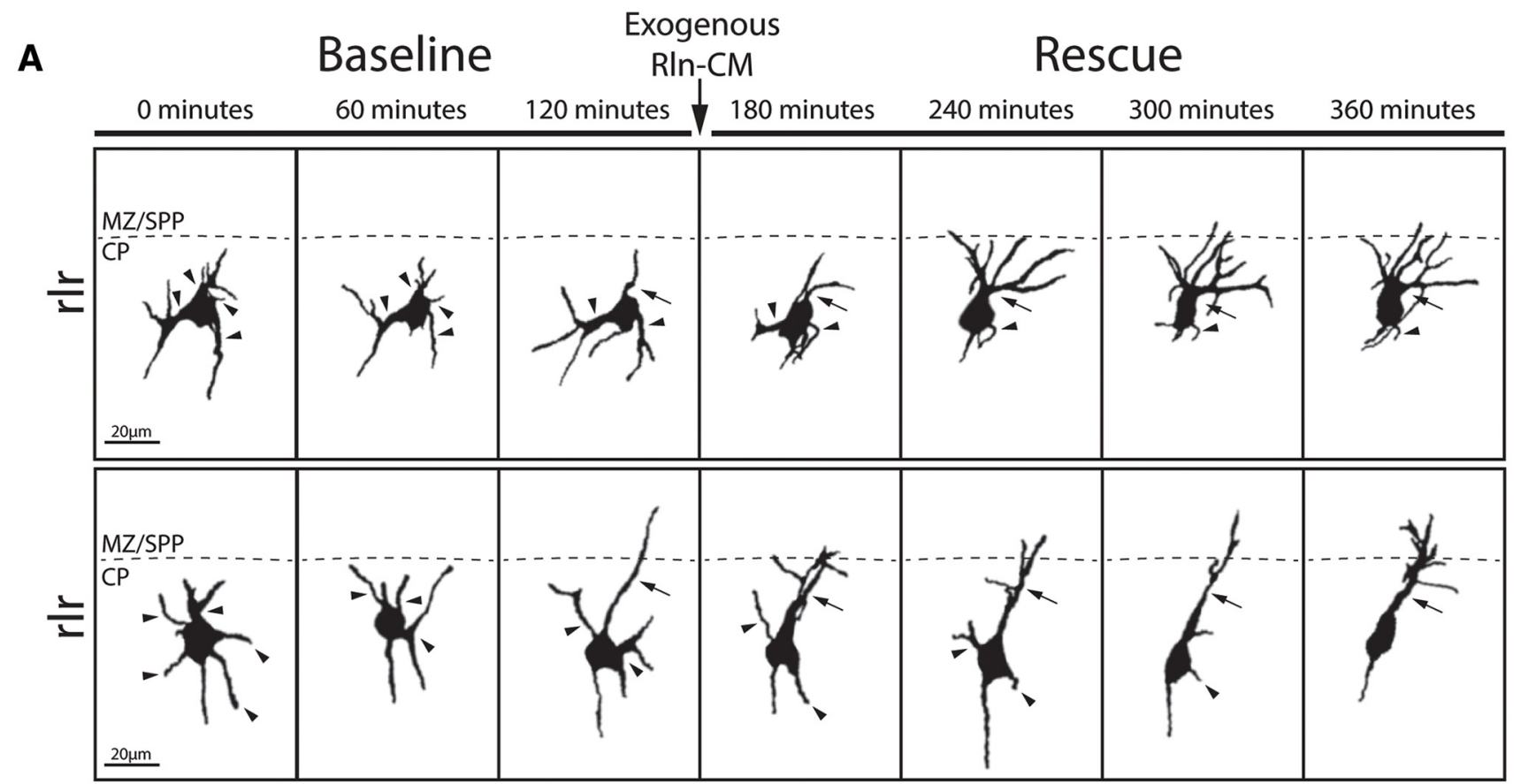

B
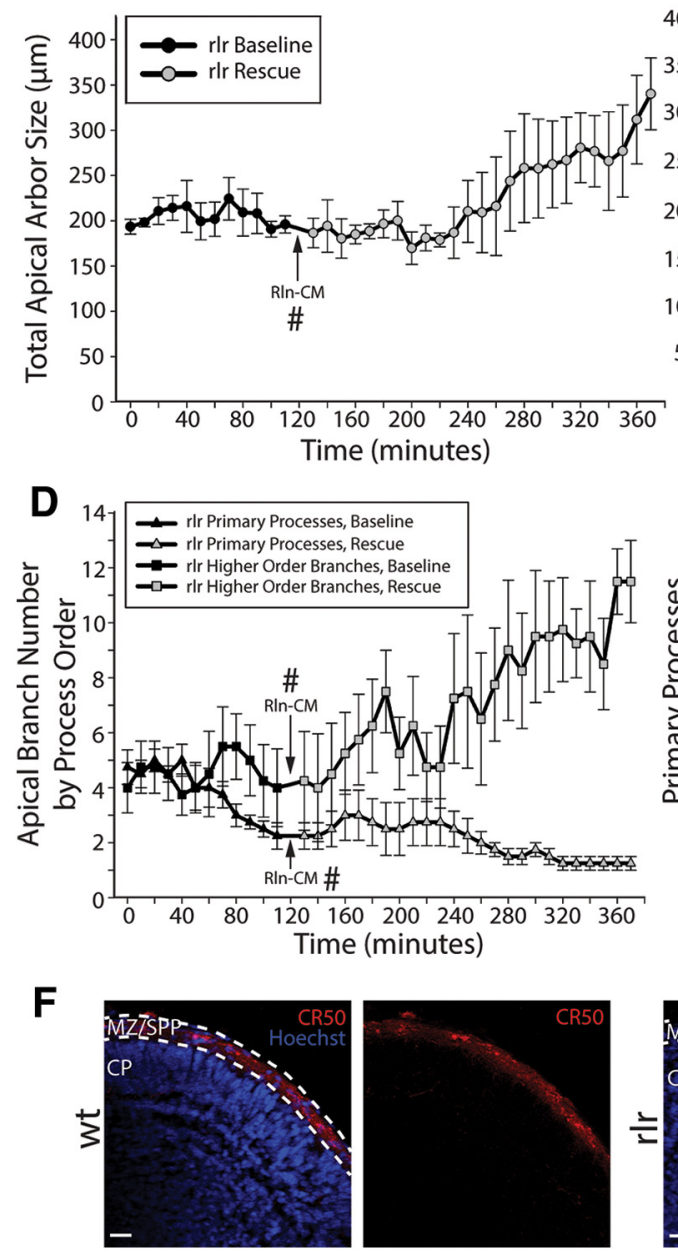

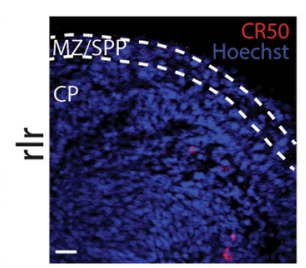

C
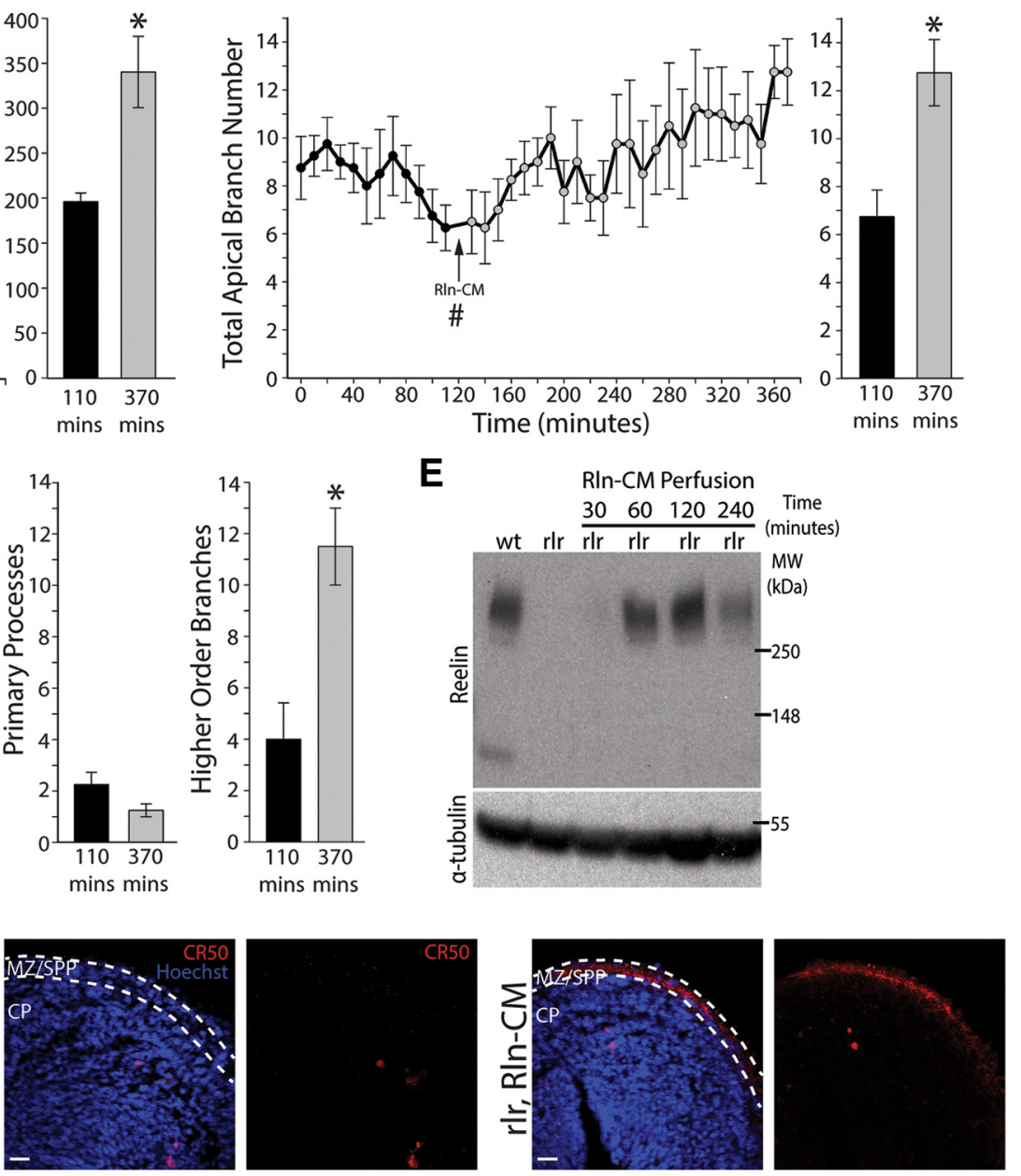

Figure 5. Reelin application causes rapid neuronal reorientation and radially directed dendritic growth in reeler cortices. $\boldsymbol{A}$, Representations of flattened ( $z$-projected) postmigratory neurons in WT and rlr explants before and after the application of RIn-CM. Before Rln-CM application, rlr neurons were misoriented and multipolar. After Rln-CM application, neurons retracted tangential primary processes (arrowheads) and elaborated a highly branched apical arbor into the overlying MZ/SPP (arrows; $\boldsymbol{A}-\boldsymbol{C}$ ). Quantitative analysis of total apical arbor size (B) and branching ( $\boldsymbol{C}$ ) over time revealed significant increases in both measures after the application of RIn-CM, in addition to decreases in primary process number and increases in higher order branch number ( $\boldsymbol{D})$. Exogenous Reelin protein was detected in rlr explants after $1 \mathrm{~h}$ of Rln-CM perfusion at levels comparable to native Reelin protein in WT explants (E). Using an anti-Reelin (Figure legend continues.) 


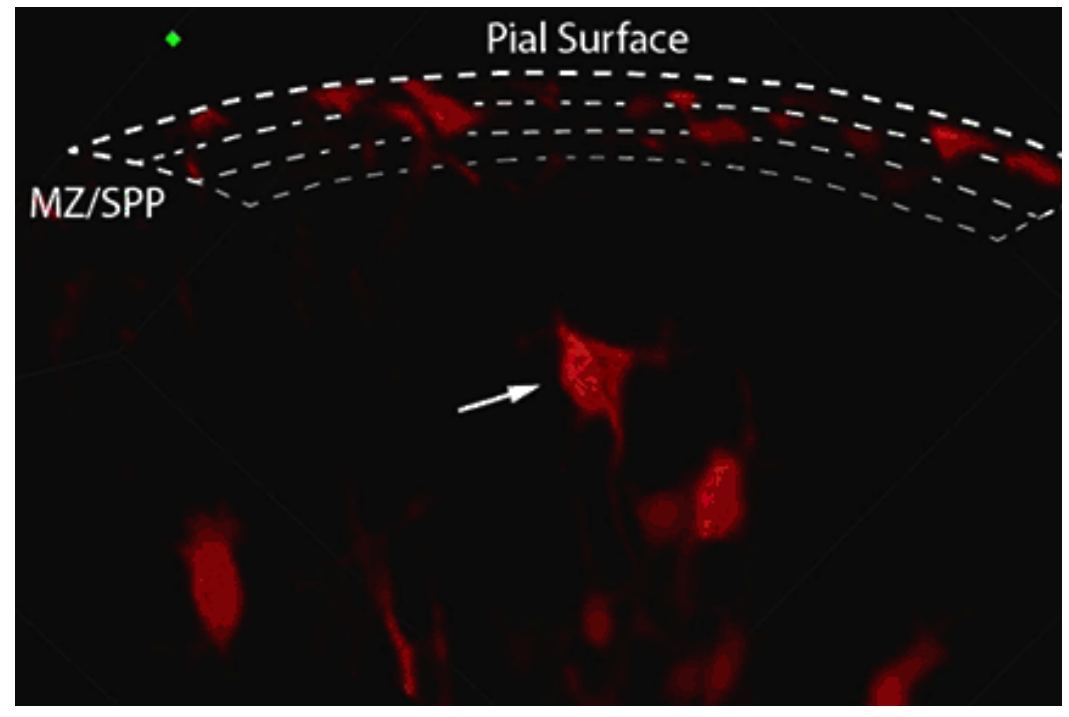

Movie 3. 4D response of a postmigratory neuron in a reeler explant treated with Reelin-conditioned medium. During baseline image acquisition (0-120 min), postmigratory rlr neurons displayed typical mutant neurite arbor dynamics characterized by multipolar morphologies, sparse higher-order branching, and a general avoidance of the overlying MZ/SPP. After the application of RIn-CM, misoriented primary processes were retracted simultaneously with the extension of an apically oriented primary neurite that grew into the overlying MZ/SPP (120-370 min). z-series were acquired at $10 \mathrm{~min}$ intervals for $6 \mathrm{~h} \mathrm{(0-370} \mathrm{min)} \mathrm{and} \mathrm{Rln-CM}$ was added at $120 \mathrm{~min}$. Time bar in lower left corner denotes the time of acquisition. A white arrow denotes the neuron of interest and dashed lines represent the overlying pial surface. Scale bars, $20 \mu \mathrm{m}$.

to similar overall arbor growth rates $(+27.6 \mathrm{vs}+18.3 \mu \mathrm{m} / \mathrm{h}, p=$ 0.435 ). Throughout the subsequent $4 \mathrm{~h}$ imaging period, however, this nonsignificant difference in growth rate produced a modest but significant difference in total arbor size between WT and reeler neurons (Fig. 4E).

WT neurites of all branch orders were longer lived compared with reeler (Fig. $4 B, C$ ). The majority of WT primary neurites were stable for the entire imaging period (and presumably the entire life of the neuron), whereas the majority of reeler primary neurites were not (Fig. 4B). When the location of the primary neurite was considered, the difference was more dramatic: WT primary neurites in the MZ/SPP had an average life span of $212 \mathrm{~min}$ (within the $240 \mathrm{~min}$ imaging period) compared with $23 \mathrm{~min}$ for reeler primaries $(p<0.001$; Fig. $4 D)$. Interestingly, reeler primaries outside the MZ/SPP were more stable than both WT primaries outside the MZ/SPP (73 vs $39 \mathrm{~min}, p=0.018$ ) and reeler primaries inside the MZ/SPP (73 vs $23 \mathrm{~min}, p<0.001$ ). Therefore, WT primary neurites are more stable in the MZ/SPP, whereas reeler primary neurites are more stable out of the MZ/SPP.

Prior studies have suggested that Reelin signaling promotes polarized neurite growth (Matsuki et al., 2010; Miyata et al., 2010; Nichols and Olson, 2010; Jossin and Cooper, 2011; O'Dell et al., 2012). If this is the case, then exogenous Reelin application to reeler explants might enhance the polarized growth of radial neu-

\section{$\leftarrow$}

(Figure legend continued.) antibody (CR50), exogenous Reelin was immunolocalized to the $\mathrm{MZ} / \mathrm{SPP}$ in fixed rlr explants after $4 \mathrm{~h}$ of perfusion with RIn-CM $(\boldsymbol{F})$. For both immunoblot $(\boldsymbol{E})$ and immunofluorescence $(\boldsymbol{F})$ assays, WT and rlr control explants were perfused for $4 \mathrm{~h}$ in medium that lacked Reelin before lysis or fixation. Dashed lines in $A$ represent the MZ-SPP/CP boundary. Error bars indicate SEM. One-way repeated-measures ANOVA with post hoc Holm-Sidak multiple-comparison procedures were performed across time to determine any significant changes in total apical arbor growth $(\boldsymbol{B})$ and branching $(\boldsymbol{C})$ after Reelin application. \#p $<0.01$ denoting a significant change over time; ${ }^{*} p<0.05$, compared with pre-Reelin application (110 min). rlr-Rescue analysis: 4 neurons from 4 explants across 4 litters. Scale bars in $\boldsymbol{A}$ and $\boldsymbol{F}, 20 \mu \mathrm{m}$. rites while simultaneously stimulating neurite retraction of tangential, misoriented neurites. Alternatively, Reelin signaling might globally stimulate neurite growth or stimulate growth of radial neurites alone. Consistent with the polarity model, within $4 \mathrm{~h}$ of recombinant Reelin application to reeler explants, a retraction of tangential neurites was observed coincident with the extension of a radially oriented process into the overlying MZ/SPP (Fig. 5; Movie 3). This structural reorganization of the neuron was accompanied by an increase in total apical arbor size and branch number (Fig. $5 B, C$ ), a loss of supernumerary primary processes, and increases in higher-order branching (Fig. $5 D$; Movie 3). To determine the amount and localization of exogenous Reelin protein in the rescue experiment, reeler explants were analyzed after Rln-CM perfusion. Reelin protein attained near WT levels after $1 \mathrm{~h}$ of application (Fig. 5E) and demonstrated an MZ/SPP-localized pattern of immunostaining that is similar to WT (Fig. 5F). This appropriate localization suggests the presence of an extracellular matrix or cellular component (Kohno et al., 2015) that may serve to anchor perfused Reelin. The application of exogenous Reelin also reduced neurite extension and retraction velocities toward values associated with WT postmigratory neurons and significantly increased the number of extension events compared with the reeler baseline (Table 3). This result shows that the acute consequence of Reelin signaling is neurite reorganization and neurite growth in the MZ/SPP and is consistent with our prior finding that Reelin rescues neuronal orientation and dendritic projection patterns within $4 \mathrm{~h}$ of application (O’Dell et al., 2012).

Reelin signaling has been proposed to promote leading process adhesion to CR cells via stabilization of membrane bound $N$-cadherin (Franco et al., 2011) and nectin3 (Gil-Sanz et al., 2013). This raises the possibility that Reelin signaling stabilizes dendritic arbors by enhancing the adhesion between developing apical neurites and the processes of CR cells in the MZ/SPP. Therefore, the spatial relationship between the dendritic filopodia of cortical neurons expressing tdTomato and CR cells expressing eGFP was examined in Pde1C::eGFP ${ }^{+}$reeler and WT explants. Unfortunately, due to lower resolution in the axial dimension and difficulties in visualizing the fine caliber processes of $\mathrm{eGFP}^{+} \mathrm{CR}$ cells, no definitive assessments could be made regarding the spatial relationship between ddTomato $^{+}$developing neurites and CR cells from the analysis of the live imaging data. Therefore, explants were prepared, fixed, and imaged with a confocal microscope at higher axial resolution $(0.2 \mu \mathrm{m}$ steps $)$ to ascertain possible neurite-CR cell relationships. Again, no consistent pattern of dendrite contact with larger CR cell bodies or processes was observed (Fig. 6A). However, these higherresolution imaging conditions failed to detect the finest $\mathrm{eGFP}^{+}$ axons emanating from the CR cells.

To examine possible Reelin-dependent spatial interactions between dendritic filopodia and the fine axonal processes localized to the MZ/SPP (including CR cell processes), electroporated mRFP-expressing cortical neurons were analyzed in fixed sec- 
Table 3. Application of exogenous Reelin to reeler mutant explants alters neurite dynamics

\begin{tabular}{|c|c|c|c|c|c|c|}
\hline & $\begin{array}{l}\text { Neurite extension } \\
\text { velocities ( } \mu \mathrm{m} / \mathrm{min})\end{array}$ & $\begin{array}{l}\text { Neurite retraction } \\
\text { velocities ( } \mu \mathrm{m} / \mathrm{min})\end{array}$ & $\begin{array}{l}\text { Extension events (\%) } \\
\text { (events observed) }\end{array}$ & $\begin{array}{l}\text { Retraction events (\%) } \\
\text { (events observed) }\end{array}$ & $\begin{array}{l}\text { Total arbor } \\
\text { growth }(\mu \mathrm{m})\end{array}$ & $\begin{array}{l}\text { Arbor growth } \\
\text { rate }(\mu \mathrm{m} / \mathrm{h})\end{array}$ \\
\hline \multicolumn{7}{|c|}{ reeler (rlr) rescue ( $n=4$ cells) } \\
\hline Baseline (0-2h) & $0.78 \pm 0.10$ & $-0.69 \pm 0.09$ & $45.9 \pm 1.7(54.8 \pm 8.7)$ & $54.1 \pm 1.7(63.5 \pm 6.9)$ & $-6.9 \pm 16.7$ & $-3.4 \pm 8.4$ \\
\hline Rescue (4-6h) & $0.66 \pm 0.06$ & $-0.58 \pm 0.05$ & $53.3 \pm 1.7^{*}(89.0 \pm 13.1)$ & $46.7 \pm 1.7^{*}(79.5 \pm 14.4)$ & $128.9 \pm 42.7^{*}$ & $64.4 \pm 21.3^{*}$ \\
\hline
\end{tabular}

Quantitative analysis of neurite extension and retraction dynamics on a per cell basis revealed that application of RIn-CM resulted in a trend towards decreased extension and retraction velocities. During baseline acquisitions, rlr neurite arbors demonstrated significantly more retraction than extension events. However, application of RIn-CM resulted in a significant increase in extension events and arbor growth rate into the overlying MZ/SPP during hours $2-4$ of the rescue. Error bars denote SEM. Two-way ANOVA with post hoc Holm-Sidak pairwise multiple comparison procedures were performed between treatment phase (baseline $0-2 \mathrm{~h}$, rescue $2-4 \mathrm{~h}$, and rescue $4-6 \mathrm{~h}$ ) and extension/retraction dynamics on a per cell basis.

${ }^{*} p<0.05$ compared with baseline of the Reelin rescue. Quantitative analysis was run on the same traced data sets presented in Figure 5 .

tions immunolabeled for the axonal neurofilament Smi312 (Fig. $6 B-F)$. High-resolution confocal $z$-series were acquired of equivalently positioned neurons and analyzed for areas of potential neurite-axon interaction, which we termed CCAs (Fig. $6 B, C$ ). A CCA was defined as a region containing pixels with suprathreshold signal on both the red dendrite (mRFP) and green axon (Smi312) channels, which indicates colocalization of the dendrite and axon to within the approximate $(790 \mathrm{~nm})$ axial resolution of the system (see Materials and Methods). The CCAs were identified in each $z$-slice and used to reconstruct a map of possible contact points on the 3D rendered image (Fig. $6 B-D$ ). As a positive control for this method, we examined the spatial overlap between leading processes of migrating neurons and anti-nestin immunolabeled radial glial fibers (Fig. $6 D, F$ ). In this control case, $34 \%$ of the leading processes were in CCAs with a nestin ${ }^{+}$ radial glia fiber.

WT neurite arbors had $2.3 \%$ of their arbor and somata within a CCA compared with $1 \%$ of reeler arbors (Fig. $6 E$ ). However, reeler neurites would be expected to have a lower percentage of dendrites in CCAs because their dendrites are largely excluded from overlying MZ/SPP (O'Dell et al., 2012), in which CR axons are primarily located. Therefore, the analyses were repeated focusing only on the dendritic processes localized to the MZ/SPP (corresponding to an area $\sim 15 \mu \mathrm{m}$ below the pial surface). In this case, there was no significant difference between WT and reeler CCA percentages (Fig. $6 \mathrm{~F}$ ). This finding argues against a model in which Reelin signaling promotes dendritic stabilization via enhancement of dendrite-axon contacts. To determine whether the neurite/axonal overlap was greater than that expected by random neurite growth within the MZ/SPP, the nascent dendritic arbor was randomized (via $z$-stack shuffling of the dendrite optical channel) and the percent overlap with the nonshuffled axonal optical channel was determined (see Materials and Methods). There was no difference in percent CCA overlap for either WT or reeler cortices after this neurite shuffling (Fig. $6 F)$. Although the analysis here cannot definitively resolve actual points of cell-cell adhesion, the observation that, independent of Reelin signaling, $\sim 97 \%$ of the neurite arbor does not spatially coincide with axonal processes suggests that dendrite/ECM interactions dominate the initial steps of dendritic growth in the cortex.

\section{Discussion}

This study characterized dynamic events associated with the initiation of cortical neurons' apical dendrites and their relationship to terminal translocation and migration arrest. Although much is known about dendritic initiation in other contexts, including cultured hippocampal neurons (Dotti and Banker, 1987; Dotti et al., 1988; Niu et al., 2004; MacLaurin et al., 2007), for actively migrating cortical neurons in situ, it was unclear whether the apical dendrite emerges via direct transformation of the leading process or emerges de novo in the postmigratory period (Ramon y Cajal, 1904). Similarly, it was unclear whether Reelin controls migration and dendritic growth in situ as related or separate processes.

Direct observation using multiphoton time-lapse imaging demonstrated that, upon contact with the overlying MZ/SPP, leading processes of both WT and reeler early born cortical neurons transform into highly branched dendritic arbors (Fig. 2). Remarkably, the longest lived stable branch point formed within 15 min of leading process contact with the MZ/SPP and was located at the boundary of the CP and MZ/SPP within one cell diameter of the final soma position upon migration arrest (Fig. 3). These observations suggest that dendritic growth and branching may function as a component of a "go signal" for terminal translocation, whereas a stable branch point formed by the nascent dendrite near the MZ-SPP/CP border functions as a "stop signal." In the absence of Reelin signaling, a significantly lower percentage of translocating neurons were observed and these neurons showed apical arbor retraction soon after the completion of translocation (Fig. 2). The inability of reeler postmigratory neurons to establish an apical dendrite prompted the elaboration of multiple tangentially oriented primary processes and a loss of overt morphological polarity.

This loss of polarity can be reversed within $\sim 2 \mathrm{~h}$ of Reelin application: the misoriented primary neurites of reeler mutant neurons are retracted coincidentally with the extension of a radially oriented primary process that displays significant arbor growth and branching into the MZ/SPP. Although the Reelin response involves neurite stabilization in the radial direction, we find that the response also involves destabilization and retraction of neurites in the tangential direction. In addition, this reorganization toward the radial direction occurs before significant total arbor growth (Fig. 5; O'Dell et al., 2012), suggesting that the initial, and perhaps primary, function of Reelin signaling involves organizing the polarity of neurons with respect to the overlying $\mathrm{MZ/SPP}$ and pial surface.

Therefore, our findings on neurite dynamics are consistent with a model of Reelin signaling wherein Reelin permits the polarized growth of neurites (Goffinet, 1979; Jossin and Goffinet, 2007; Matsuki et al., 2010; Miyata et al., 2010; Nichols and Olson, 2010; Jossin and Cooper, 2011; Schneider et al., 2011; O'Dell et al., 2012). The polarity disruptions manifest early in cortical development during the period of preplate splitting, when L6 neurons in reeler cortices, although correctly positioned, remain tangentially orientated and fail to coalesce and align in the radial direction (Nichols and Olson, 2010). Instead of exhibiting a single, radially oriented process, reeler neurons are characterized by multiple tangentially oriented primary processes (O’Dell et al., 2012), suggesting a funda- 
A
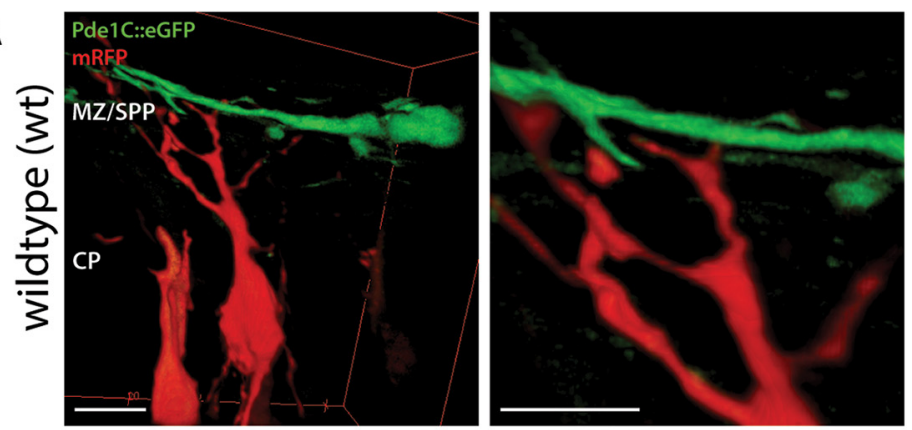

B
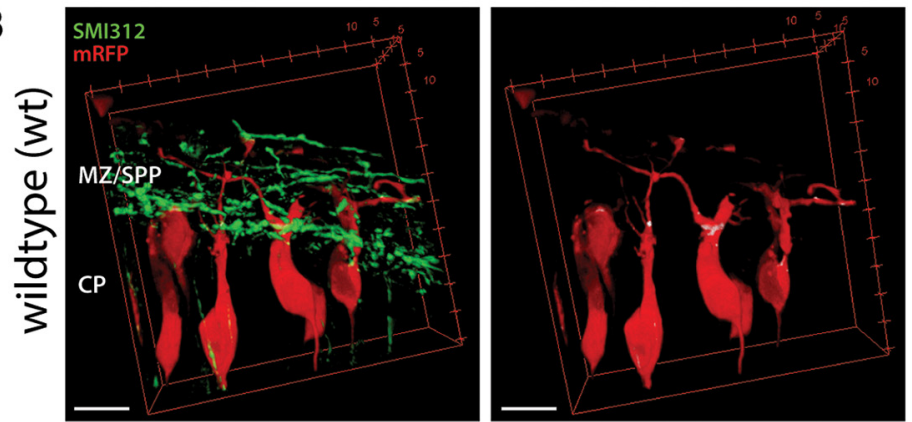

C
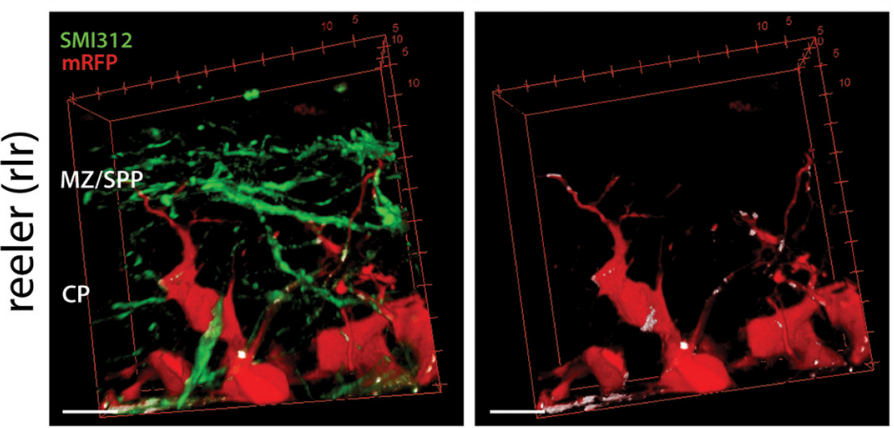

D
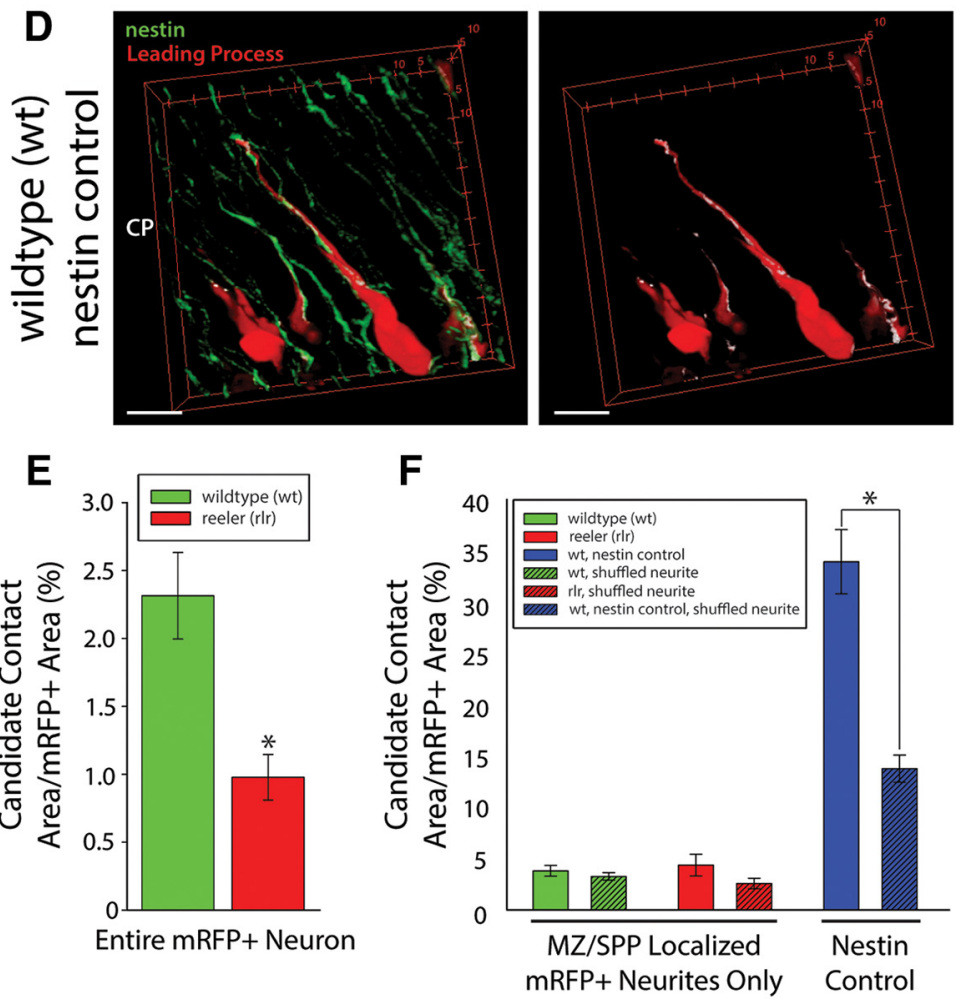

Figure 6. Candidate contact areas between developing neurites and MZ/SPP axons are not affected by Reelin deficiency. $\boldsymbol{A}$, No consistent areas of contact were observed between mRFP-expressing cortical neurites and eGFP-expressing cell bodies or dendrites mental disruption of the mechanisms that control polarized dendritic outgrowth (Bradke and Dotti, 2000; Horton and Ehlers, 2003; Gärtner et al., 2012). Later in development, a similar Reelin-dependent polarization occurs during the transition of multipolar neurons in the intermediate zone to bipolar migrating neurons in the developing $\mathrm{CP}$ (Jossin and Cooper, 2011).

This polarization model, however, is difficult to reconcile with the observation that $41 \%$ of the imaged neurons failed to translocate terminally when Reelin signaling is blocked. In addition, prior studies have found that cell autonomous suppression or knock-out of Dab1 causes migrating neurons to arrest $\sim 40 \mu \mathrm{m}$ below and prevents normal dendritic arborization into the MZ/SPP (Olson et al., 2006; Franco et al., 2011; Sekine et al., 2012). These neurons are nevertheless morphologically polarized along the radial glial fiber with a clear leading process and trailing axon. How can the absence of a Reelin-dependent polarizing signal contribute to the failure to initiate translocation in a morphologically polarized cell?

One possibility is that, during terminal translocation, the neuron must transition from polarity defined by the radial glial substrate to polarity defined by the orientation of the apical dendrite. During the translocation period, the mi-

\section{$\leftarrow$}

of CR cells (Pde1C::eGFP transgenic embryo). CCA analysis identifies regions where mRFP-expressing cortical neurites (red) and Smi312-immunopositive MZ/SPP axons (green) cannot be spatially resolved (i.e., are within $790 \mathrm{~nm}) \cdot \boldsymbol{B}-\boldsymbol{D}$, CCAs are represented in white and superimposed over the mRFP ${ }^{+}$ signal (second column). CCA is higher in WT (B) compared with rlr mutantneurons ( () when the entire RFP ${ }^{+}$arbor is analyzed (E). $\boldsymbol{F}$, CCA analysis revealed no significant differences between WT and rlr neurons when analyses are restricted to MZ/ SPP localized neurites. In addition, no significant differences in CCAs between WT and rlr explants were observed after z-stack shuffling of the dendrite, suggesting random dendrite/axon interactions account for measured the CCAs. As a positive control, CCA analysis was applied to mRFP ${ }^{+}$leading processes apposed to nestin expressing radial glial fibers $(\boldsymbol{D}, \boldsymbol{F})$. This analysis revealed an expected high percentage of the leading process forming within (CAs, as well as a significant decrease when the leading process $z$-stack was randomly shuffled $(\boldsymbol{F})$. Error bars indicate SEM. Two-way ANOVA was performed to assess CCA differences. ${ }^{*} p<0.05$ compared with WT or non$z$-shuffled controls. WT whole-field analysis: 22 image fields from 11 explants across 11 litters. WT MZ/SPP analysis: $22 \mathrm{im}$ age fields from 11 explants across 11 litters. rlr whole-field analysis: 13 image fields from 6 explants across 6 litters. Ir MZ/SPP analysis: 14 image fields from 7 explants across 7 litters. WT nestin control analysis: 37 leading processes from 5 explants across 5 litters. Scale bars in $\mathbf{A}-\mathbf{D}, 10 \mu \mathrm{m}$. Pde 1 , Phosphodiesterase $1 C$. 
grating neuron releases from the radial glial process (Nadarajah et al., 2001). At the same time, we find that the neuronal arbor increases $\sim 2.5$-fold in size, with most of this new growth localized to the extracellular matrix of the MZ/SPP. Therefore, new adhesion and polarity systems must be deployed to guide the growing arbor. This dendrite-based polarity depends on extrinsic signals including Semaphorin 3a (Polleux et al., 2000) and Reelin (O'Dell et al., 2012), as well as intrinsic signaling involving LKB/Strad $\alpha$ kinase (Barnes et al., 2007; Matsuki et al., 2010) that coordinate the deployment of the Golgi apparatus (Matsuki et al., 2010) and the polarized deployment of $\mathrm{N}$-cadherin (Franco et al., 2011; Jossin and Cooper, 2011; Jossin, 2011; Gärtner et al., 2012). Reelindependent polarity signals might also enhance neurite adhesion to MZ/SPP cells (Franco et al., 2011; Gil-Sanz et al., 2013) or to the surrounding MZ/SPP ECM (Sekine et al., 2012). Absent Reelin signaling, decreased neurite adhesion, and reduced deployment of the Golgi would lead to an inability to establish a stable apical arbor in the MZ/SPP (Chai et al., 2009) and subsequent failure to initiate translocation for approximately half of the imaged neurons (Fig. 1). Neurons that fail to translocate might deploy an unstable branched dendritic arbor through a Reelin-independent default process, which further impairs radial translocation through somal arrest at ectopic branch points (Fig. 3). For neurons that translocate successfully, the inability to stabilize the apical dendrite after translocation leads to arbor reorganization and loss of morphologic polarity (Figs. 2, 4). In this model, Golgi deployment would function as an effector of the polarity signal to stabilize the apically directed dendritic arbor selectively at the expense of tangentially oriented arbors (Horton et al., 2005). Golgi deployment might serve multiple functions, including providing membrane and appropriately modified adhesion molecules underlying dendritic growth (Futerman and Banker, 1996; Horton et al., 2005; Wu et al., 2015), as well as functioning as a microtubule nucleating center for the apical dendrite (Ori-McKenney et al., 2012).

This work expands our earlier analysis of Reelin-dependent neurite growth and orientation angles, suggesting that a critical function of Reelin signaling during early cortical development is to render neurites competent for growth into the MZ/ SPP (O'Dell et al., 2012). The orientation of cell bodies and the distribution of neurites in reeler mutant cortices are tangential, not random. A random distribution of orientations would be expected in reeler cortices if Reelin functioned exclusively as a positive extrinsic cue for polarized growth. Moreover, neurites that grow into the mutant MZ/SPP often retract quickly. This observation strongly suggests the presence of an $\mathrm{MZ/SPP-localized} \mathrm{inhibitor} \mathrm{that} \mathrm{is} \mathrm{overridden} \mathrm{by} \mathrm{intact} \mathrm{Reelin}$ signaling. This inhibitor could simply represent an anti-adhesive component of the MZ/SPP. Alternatively, the inhibitor could be an active chemorepellent. Because the hypothesized inhibitor prevents, in the absence of Reelin, appropriate projection of the leading process and dendrite, reeler neurons are unable to polarize appropriately. Although the molecular identity of this putative inhibitor is unknown, it is intriguing that two of the locations where Reelin signaling apparently operates, the MZ/SPP and the subplate (the junction between the intermediate zone and CP), have extensive axonal elaborations during early cortical development. We speculate that a normal function of this inhibitor is to prevent inappropriate connections between developing leading processes/ dendrites and an overlying axonal plexus.

\section{References}

Armstrong DD, Dunn K, Antalffy B (1998) Decreased dendritic branching in frontal, motor and limbic cortex in Rett syndrome compared with trisomy 21. J Neuropathol Exp Neurol 57:1013-1017. CrossRef Medline

Barnes AP, Lilley BN, Pan YA, Plummer LJ, Powell AW, Raines AN, Sanes JR, Polleux F (2007) LKB1 and SAD kinases define a pathway required for the polarization of cortical neurons. Cell 129:549-563. CrossRef Medline

Bradke F, Dotti CG (2000) Establishment of neuronal polarity: lessons from cultured hippocampal neurons. Curr Opin Neurobiol 10:574-581. CrossRef Medline

Caviness VS Jr (1982) Neocortical histogenesis in normal and reeler mice: a developmental study based upon [3H]thymidine autoradiography. Brain Res 256:293-302. Medline

Caviness VS Jr, Sidman RL (1973) Time of origin or corresponding cell classes in the cerebral cortex of normal and reeler mutant mice: an autoradiographic analysis. J Comp Neurol 148:141-151. CrossRef Medline

Chai X, Förster E, Zhao S, Bock HH, Frotscher M (2009) Reelin stabilizes the actin cytoskeleton of neuronal processes by inducing $\mathrm{n}$-cofilin phosphorylation at serine3. J Neurosci 29:288-299. CrossRef Medline

Chai X, Fan L, Shao H, Lu X, Zhang W, Li J, Wang J, Chen S, Frotscher M, Zhao S (2014) Reelin induces branching of neurons and radial glial cells during corticogenesis. Cereb Cortex. In press.

Cooper JA (2008) A mechanism for inside-out lamination in the neocortex. Trends Neurosci 31:113-119. CrossRef Medline

D’Arcangelo G, Miao GG, Chen SC, Soares HD, Morgan JI, Curran T (1995) A protein related to extracellular matrix proteins deleted in the mouse mutant reeler. Nature 374:719-723. CrossRef Medline

De Rubeis S, He X, Goldberg AP, Poultney CS, Samocha K, Cicek AE, Kou Y, Liu L, Fromer M, Walker S, Singh T, Klei L, Kosmicki J, Shih-Chen F, Aleksic B, Biscaldi M, Bolton PF, Brownfeld JM, Cai J, Campbell NG, et al. (2014) Synaptic, transcriptional and chromatin genes disrupted in autism. Nature 515:209-215. CrossRef Medline

Demyanenko GP, Halberstadt AI, Rao RS, Maness PF (2010) CHL1 cooperates with PAK1-3 to regulate morphological differentiation of embryonic cortical neurons. Neuroscience 165:107-115. CrossRef Medline

Dijkhuizen PA, Ghosh A (2005) Regulation of dendritic growth by calcium and neurotrophin signaling. Prog Brain Res 147:17-27. Medline

Dotti CG, Banker GA (1987) Experimentally induced alteration in the polarity of developing neurons. Nature 330:254-256. CrossRef Medline

Dotti CG, Simons K (1990) Polarized sorting of viral glycoproteins to the axon and dendrites of hippocampal neurons in culture. Cell 62:63-72. CrossRef Medline

Dotti CG, Sullivan CA, Banker GA (1988) The establishment of polarity by hippocampal neurons in culture. J Neurosci 8:1454-1468. Medline

Dulabon L, Olson EC, Taglienti MG, Eisenhuth S, McGrath B, Walsh CA, Kreidberg JA, Anton ES (2000) Reelin binds alpha3betal integrin and inhibits neuronal migration. Neuron 27:33-44. CrossRef Medline

Franco SJ, Martinez-Garay I, Gil-Sanz C, Harkins-Perry SR, Müller U (2011) Reelin regulates cadherin function via Dab1/Rap1 to control neuronal migration and lamination in the neocortex. Neuron 69:482-497. CrossRef Medline

Futerman AH, Banker GA (1996) The economics of neurite outgrowth-the addition of new membrane to growing axons. Trends Neurosci 19:144149. CrossRef Medline

Gärtner A, Fornasiero EF, Munck S, Vennekens K, Seuntjens E, Huttner WB, Valtorta F, Dotti CG (2012) N-cadherin specifies first asymmetry in developing neurons. EMBO J 31:1893-1903. CrossRef Medline

Gil-Sanz C, Franco SJ, Martinez-Garay I, Espinosa A, Harkins-Perry S, Müller U (2013) Cajal-Retzius cells instruct neuronal migration by coincidence signaling between secreted and contact-dependent guidance cues. Neuron 79:461-477. CrossRef Medline

Goffinet AM (1979) An early development defect in the cerebral cortex of the reeler mouse: a morphological study leading to a hypothesis concerning the action of the mutant gene. Anat Embryol 157:205-216. CrossRef Medline

Goffinet AM, Lyon G (1979) Early histogenesis in the mouse cerebral cortex: a Golgi study. Neurosci Lett 14:61-66. CrossRef Medline

Hatanaka Y, Murakami F (2002) In vitro analysis of the origin, migratory behavior, and maturation of cortical pyramidal cells. J Comp Neurol 454:1-14. CrossRef Medline

Hatanaka Y, Yamauchi K (2013) Excitatory cortical neurons with multipolar shape establish neuronal polarity by forming a tangentially oriented 
axon in the intermediate zone. Cereb Cortex 23:105-113. CrossRef Medline

Hirotsune S, Takahara T, Sasaki N, Hirose K, Yoshiki A, Ohashi T, Kusakabe M, Murakami Y, Muramatsu M, Watanabe S (1995) The reeler gene encodes a protein with an EGF-like motif expressed by pioneer neurons. Nat Genet 10:77-83. CrossRef Medline

Hong SE, Shugart YY, Huang DT, Shahwan SA, Grant PE, Hourihane JO, Martin ND, Walsh CA (2000) Autosomal recessive lissencephaly with cerebellar hypoplasia is associated with human RELN mutations. Nat Genet 26:93-96. CrossRef Medline

Horton AC, Ehlers MD (2003) Neuronal polarity and trafficking. Neuron 40:277-295. CrossRef Medline

Horton AC, Rácz B, Monson EE, Lin AL, Weinberg RJ, Ehlers MD (2005) Polarized secretory trafficking directs cargo for asymmetric dendrite growth and morphogenesis. Neuron 48:757-771. CrossRef Medline

Hourihane JO, Bennett CP, Chaudhuri R, Robb SA, Martin ND (1993) A sibship with a neuronal migration defect, cerebellar hypoplasia and congenital lymphedema. Neuropediatrics 24:43-46. CrossRef Medline

Jan YN, Jan LY (2003) The control of dendrite development. Neuron 40: 229-242. CrossRef Medline

Jareb M, Banker G (1998) The polarized sorting of membrane proteins expressed in cultured hippocampal neurons using viral vectors. Neuron 20:855-867. CrossRef Medline

Jossin Y (2011) Polarization of migrating cortical neurons by Rapl and Ncadherin: revisiting the model for the Reelin signaling pathway. Small GTPases 2:322-328. CrossRef Medline

Jossin Y, Cooper JA (2011) Reelin, Rap1 and N-cadherin orient the migration of multipolar neurons in the developing neocortex. Nat Neurosci 14:697-703. CrossRef Medline

Jossin Y, Goffinet AM (2007) Reelin signals through phosphatidylinositol 3-kinase and Akt to control cortical development and through mTor to regulate dendritic growth. Mol Cell Biol 27:7113-7124. CrossRef Medline

Kohno T, Honda T, Kubo K, Nakano Y, Tsuchiya A, Murakami T, Banno H, Nakajima K, Hattori M (2015) Importance of Reelin C-terminal region in the development and maintenance of the postnatal cerebral cortex and its regulation by specific proteolysis. J Neurosci 35:4776-4787. CrossRef Medline

Krey JF, Paşca SP, Shcheglovitov A, Yazawa M, Schwemberger R, Rasmusson R, Dolmetsch RE (2013) Timothy syndrome is associated with activitydependent dendritic retraction in rodent and human neurons. Nat Neurosci 16:201-209. CrossRef Medline

Longair MH, Baker DA, Armstrong JD (2011) Simple Neurite Tracer: open source software for reconstruction, visualization and analysis of neuronal processes. Bioinformatics 27:2453-2454. CrossRef Medline

MacLaurin SA, Krucker T, Fish KN (2007) Hippocampal dendritic arbor growth in vitro: regulation by Reelin-Disabled-1 signaling. Brain Res 1172:1-9. CrossRef Medline

Matsuda T, Cepko CL (2004) Electroporation and RNA interference in the rodent retina in vivo and in vitro. Proc Natl Acad Sci U S A 101:16-22. CrossRef Medline

Matsuki T, Matthews RT, Cooper JA, van der Brug MP, Cookson MR, Hardy JA, Olson EC, Howell BW (2010) Reelin and stk25 have opposing roles in neuronal polarization and dendritic Golgi deployment. Cell 143:826836. CrossRef Medline

McAllister AK (2002) Conserved cues for axon and dendrite growth in the developing cortex. Neuron 33:2-4. CrossRef Medline

Miyata T, Ono Y, Okamoto M, Masaoka M, Sakakibara A, Kawaguchi A, Hashimoto M, Ogawa M (2010) Migration, early axonogenesis, and Reelin-dependent layer-forming behavior of early/posterior-born Purkinje cells in the developing mouse lateral cerebellum. Neural Dev 5:23. CrossRef Medline

Miyazaki J, Takaki S, Araki K, Tashiro F, Tominaga A, Takatsu K, Yamamura K (1989) Expression vector system based on the chicken beta-actin promoter directs efficient production of interleukin-5. Gene 79:269-277. CrossRef Medline

Nadarajah B, Brunstrom JE, Grutzendler J, Wong RO, Pearlman AL (2001) Two modes of radial migration in early development of the cerebral cortex. Nat Neurosci 4:143-150. CrossRef Medline

Nichols AJ, Olson EC (2010) Reelin promotes neuronal orientation and dendritogenesis during preplate splitting. Cereb Cortex 20:2213-2223. CrossRef Medline

Nichols AJ, O’Dell RS, Powrozek TA, Olson EC (2013) Ex utero electropo- ration and whole hemisphere explants: a simple experimental method for studies of early cortical development. J Vis Exp 74:50271. CrossRef Medline

Niu S, Renfro A, Quattrocchi CC, Sheldon M, D'Arcangelo G (2004) Reelin promotes hippocampal dendrite development through the VLDLR/ ApoER2-Dab1 pathway. Neuron 41:71-84. CrossRef Medline

Noctor SC, Martínez-Cerdeño V, Ivic L, Kriegstein AR (2004) Cortical neurons arise in symmetric and asymmetric division zones and migrate through specific phases. Nat Neurosci 7:136-144. CrossRef Medline

O'Dell RS, Ustine CJ, Cameron DA, Lawless SM, Williams RM, Zipfel WR, Olson EC (2012) Layer 6 cortical neurons require Reelin-Dab1 signaling for cellular orientation, Golgi deployment, and directed neurite growth into the marginal zone. Neural Dev 7:25. CrossRef Medline

Ogawa M, Miyata T, Nakajima K, Yagyu K, Seike M, Ikenaka K, Yamamoto H, Mikoshiba K (1995) The reeler gene-associated antigen on CajalRetzius neurons is a crucial molecule for laminar organization of cortical neurons. Neuron 14:899-912. CrossRef Medline

Olson EC, Kim S, Walsh CA (2006) Impaired neuronal positioning and dendritogenesis in the neocortex after cell-autonomous Dabl suppression. J Neurosci 26:1767-1775. CrossRef Medline

Ori-McKenney KM, Jan LY, Jan YN (2012) Golgi outposts shape dendrite morphology by functioning as sites of acentrosomal microtubule nucleation in neurons. Neuron 76:921-930. CrossRef Medline

Osheroff H, Hatten ME (2009) Gene expression profiling of preplate neurons destined for the subplate: genes involved in transcription, axon extension, neurotransmitter regulation, steroid hormone signaling, and neuronal survival. Cereb Cortex 19:i126-i134. CrossRef Medline

Pinto Lord MC, Caviness VS Jr (1979) Determinants of cell shape and orientation: a comparative Golgi analysis of cell-axon interrelationships in the developing neocortex of normal and reeler mice. J Comp Neurol 187:49-69. CrossRef Medline

Pinto-Lord MC, Evrard P, Caviness VS Jr (1982) Obstructed neuronal migration along radial glial fibers in the neocortex of the reeler mouse: a Golgi-EM analysis. Brain Res 256:379-393. Medline

Polleux F, Morrow T, Ghosh A (2000) Semaphorin 3A is a chemoattractant for cortical apical dendrites. Nature 404:567-573. CrossRef Medline

Powrozek TA, Olson EC (2012) Ethanol-induced disruption of Golgi apparatus morphology, primary neurite number and cellular orientation in developing cortical neurons. Alcohol 46:619-627. CrossRef Medline

Puram SV, Bonni A (2013) Cell-intrinsic drivers of dendrite morphogenesis. Development 140:4657-4671. CrossRef Medline

Rakic P (1972) Mode of cell migration to the superficial layers of fetal monkey neocortex. J Comp Neurol 145:61-83. CrossRef Medline

Ramon y Cajal S (1904) The histology of the nervous sytem in man and vertebrates. Oxford: OUP.

Sakakibara A, Sato T, Ando R, Noguchi N, Masaoka M, Miyata T (2014) Dynamics of centrosome translocation and microtubule organization in neocortical neurons during distinct modes of polarization. Cereb Cortex 24:1301-1310. CrossRef Medline

Sanada K, Gupta A, Tsai LH (2004) Disabled-1-regulated adhesion of migrating neurons to radial glial fiber contributes to neuronal positioning during early corticogenesis. Neuron 42:197-211. CrossRef Medline

Schapiro MB, Rosman NP, Kemper TL (1984) Effects of chronic exposure to alcohol on the developing brain. Neurobehav Toxicol Teratol 6:351356. Medline

Schneider S, Gulacsi A, Hatten ME (2011) Lrp12/Mig13a reveals changing patterns of preplate neuronal polarity during corticogenesis that are absent in reeler mutant mice. Cereb Cortex 21:134-144. CrossRef Medline

Schwartz ML, Rakic P, Goldman-Rakic PS (1991) Early phenotype expression of cortical neurons: evidence that a subclass of migrating neurons have callosal axons. Proc Natl Acad Sci U S A 88:1354-1358. CrossRef Medline

Sekine K, Kawauchi T, Kubo K, Honda T, Herz J, Hattori M, Kinashi T, Nakajima K (2012) Reelin controls neuronal positioning by promoting cell-matrix adhesion via inside-out activation of integrin alpha5beta1. Neuron 76:353-369. CrossRef Medline

Shaner NC, Campbell RE, Steinbach PA, Giepmans BN, Palmer AE, Tsien RY (2004) Improved monomeric red, orange and yellow fluorescent proteins derived from Discosoma sp. red fluorescent protein. Nat Biotechnol 22:1567-1572. CrossRef Medline 
Sheppard AM, Pearlman AL (1997) Abnormal reorganization of preplate neurons and their associated extracellular matrix: an early manifestation of altered neocortical development in the reeler mutant mouse. J Comp Neurol 378:173-179. CrossRef Medline

Tabata H, Nakajima K (2003) Multipolar migration: the third mode of radial neuronal migration in the developing cerebral cortex. J Neurosci 23:9996-10001. Medline

Takahashi T, Goto T, Miyama S, Nowakowski RS, Caviness VS Jr (1999) Sequence of neuron origin and neocortical laminar fate: relation to cell cycle of origin in the developing murine cerebral wall. J Neurosci 19: 10357-10371. Medline

Tavosanis G (2012) Dendritic structural plasticity. Dev Neurobiol 72: 73-86. CrossRef Medline
Van Aelst L, Cline HT (2004) Rho GTPases and activity-dependent dendrite development. Curr Opin Neurobiol 14:297-304. CrossRef Medline

Wang Z, Hong Y, Zou L, Zhong R, Zhu B, Shen N, Chen W, Lou J, Ke J, Zhang T, Wang W, Miao X (2014) Reelin gene variants and risk of autism spectrum disorders: an integrated meta-analysis. Am J Med Genet 165B: 192-200. Medline

Wu YK, Fujishima K, Kengaku M (2015) Differentiation of apical and basal dendrites in pyramidal cells and granule cells in dissociated hippocampal cultures. PLoS One 10:e0118482. CrossRef Medline

Yuste R, Gutnick MJ, Saar D, Delaney KR, Tank DW (1994) Ca2 ${ }^{+}$accumulations in dendrites of neocortical pyramidal neurons: an apical band and evidence for two functional compartments. Neuron 13:23-43. CrossRef Medline 